\title{
The CEO beauty premium: Founder CEO attractiveness and firm valuation in initial coin offerings
}

\author{
Massimo G. Colombo ${ }^{1}$ | Christian Fisch ${ }^{2,3}$ (1) | Paul P. Momtaz ${ }^{4,5,6,7}$ \\ Silvio Vismara ${ }^{8,9}$
}

\footnotetext{
${ }^{1}$ School of Management, Politecnico di Milano, Milan, Italy

${ }^{2}$ Faculty of Management, Trier University, Trier, Germany

${ }^{3}$ Interdisciplinary Centre for Security, Reliability and Trust (SnT), University of Luxembourg, Luxembourg, Luxembourg

${ }^{4}$ Anderson School of Management, University of California Los Angeles (UCLA), California Los Angeles, USA

${ }^{5}$ The Wharton School, University of Pennsylvania, Philadelphia, Pennsylvania, USA

${ }^{6}$ House of Finance, Goethe University

Frankfurt, Frankfurt, Germany

${ }^{7}$ Computer Science Department, Center for Blockchain Technologies, University College London, London, UK

${ }^{8}$ Department of Management, University of Bergamo, Bergamo, Italy

${ }^{9}$ Department of Accountancy and Corporate Finance, University of Ghent, Ghent, Belgium

\section{Correspondence}

Paul P. Momtaz, University of California, Los Angeles (UCLA), Anderson School of Management, 110 Westwood Plaza, Los Angeles, CA 90095, USA.

Email: momtaz@ucla.edu
}

\begin{abstract}
Research summary: We apply insights from research in social psychology and labor economics to the domain of entrepreneurial finance and investigate how founder chief executive officers' (founder CEOs') facial attractiveness influences firm valuation. Leveraging the novel context of initial coin offerings (ICOs), we document a pronounced founder CEO beauty premium, with a positive relationship between founder CEO attractiveness and firm valuation. We find only very limited evidence of stereotype-based evaluations, through the association of founder CEO attractiveness with latent traits such as competence, intelligence, likeability, or trustworthiness. Rather, attractiveness seems to bear economic value per se, especially in a context in which investors base their decisions on a limited information set. Indeed, attractiveness has a sustainable effect on post-ICO performance.

Managerial summary: ICOs allow ventures to collect funding from investors using blockchain technology. We leverage this novel funding context, in which information on the ventures and their future prospects is scarce, to empirically investigate whether the founder CEOs' physical attractiveness is associated with increased funding
\end{abstract}

This is an open access article under the terms of the Creative Commons Attribution-NonCommercial-NoDerivs License, which permits use and distribution in any medium, provided the original work is properly cited, the use is non-commercial and no modifications or adaptations are made.

(c) 2021 The Authors. Strategic Entrepreneurship Journal published by John Wiley \& Sons Ltd on behalf of Strategic Management Society. 
Funding information

The Price Center for Entrepreneurship and Innovation at UCLA (i.e., amount raised) and post-funding performance (i.e., buy-and-hold returns). We find that ventures with more attractive founder CEOs outperform ventures with less attractive CEOs in both dimensions. For ICO investors, this suggests that ICOs of firms with more attractive founder CEOs are more appealing investment targets. Our findings are also interesting for startups seeking external finance in uncertain contexts, such as ICOs. If startups can appoint attractive leaders, they may have better access to growth capital.

\section{KEYWORDS}

beauty premium, CEO attractiveness, entrepreneurial finance, firm valuation, initial coin offering, token offering

\section{1 | INTRODUCTION}

Initial coin offerings (ICOs) are a novel way for entrepreneurial ventures to raise growth capital through the blockchain-based issuance of cryptocurrency tokens (Fisch, 2019; Howell, Niessner, \& Yermack, 2020; Momtaz, 2020a). ICOs are characterized by an exceptionally large amount of uncertainty (Fisch, 2019; Lyandres, Palazzo, \& Rabetti, 2019; Momtaz, 2021a). The valuation of ICOs is challenging, as the typical ICO firm has no track record and its business model is often highly innovative and visionary. In such an uncertainty-plagued transaction context, the CEO, who generally is one of the firm's founders, is often the most salient indicator of firm quality and serves as the primary reference point for investors in ICOs (Momtaz, 2020c, 2021a). Accordingly, previous studies show that ICO valuations are related to human capital characteristics such as founders' industry backgrounds (e.g., An, Duan, Hou, \& Xu, 2019), CEO age and education (Momtaz, 2021a), team size (Lyandres et al., 2019), or expert ratings of the management team (Momtaz, 2020a).

We leverage this novel setting to assess the link between founder CEOs' attractiveness and firm valuation. Our arguments build on a growing literature that documents a "beauty premium" in very different fields of research, including psychology, politics, and labor economics (e.g., Baron, Markman, \& Bollinger, 2006; Berggren, Jordahl, \& Poutvaara, 2010; Hamermesh \& Biddle, 1994; for reviews, see Hamermesh, 2011 and Maestripieri, Henry, \& Nickels, 2017). However, how much, when, and why founder CEOs' attractiveness matters for entrepreneurial outcomes largely remain open questions.

To address this research gap, we argue that founder CEOs' facial attractiveness positively influences firm valuation in the context of ICOs where the information set on' which investors can base their decision is very limited. Our hypotheses draw on two schools of thought concerned with the advantages experienced by attractive people. Work in economics hinges on statistical discrimination theory (e.g., Arrow, 1973; Phelps, 1972) and argues that attractiveness matters because attractive individuals are more likely to develop valuable skills (e.g., social skills), which are conducive to increased productivity (e.g., Hamermesh \& Biddle, 1994). In contrast, the social psychology school ascribes "what is beautiful is good" biases to stereotype-based evaluations (e.g., Dion, Berscheid, \& Walster, 1972; Langlois et al., 2000). Denying that beauty matters per se, stereotype-based theories explain attractiveness advantages through other desirable traits associated with attractiveness, such as trustworthiness, likability, intelligence, competence, and confidence. 
Consistent with both schools of thought, our overarching hypothesis is that a "CEO beauty premium" exists. That is, founder CEO attractiveness is positively related to firm valuation in ICOs. We derive additional hypotheses by applying the arguments of each school of thought to the ICO context. First, according to the social psychology school, the CEO beauty premium may be (fully or partially) explained by investors' stereotype-based evaluations of CEO attractiveness. Specifically, other CEO traits that are desirable in ICOs (i.e., trustworthiness, competence, likability, and intelligence) may explain the attractiveness-valuation relationship through a mediating mechanism. Second, consistent with the economics school, CEO attractiveness may fill an informational void for investors in informationscarce ICOs by serving as a reference point for investment-decision heuristics. This implies a weaker CEO attractiveness-firm valuation relationship when more information is available to investors. Lastly, the study of postICO performance should reveal whether relying on CEO attractiveness is beneficial for investors in the long term, as is claimed by the economics school.

Our results suggest that founder CEO attractiveness serves as a reference point for investment decision-making in the presence of highly asymmetric information, while it plays a weaker role in information-richer contexts. This finding is relevant for both entrepreneurship and finance literatures. While the importance of founder CEOs for early-stage ventures' outcomes and access to scarce resources (e.g., growth capital) is a stylized fact, physical attributes, such as facial attractiveness, have only been rarely addressed and have not yet been linked to performance outcomes, with very few exceptions (Baron et al., 2006; Brooks, Huang, Kearney, \& Murray, 2014; Davila \& Guasch, 2020; Patel \& Wolfe, 2019). We extend this research by showing that ICO investors value companies led by attractive founder CEOs more highly, and are probably right to do so. In this way, we identify the relative explanatory power of different theoretical mechanisms underlying the founder CEOs' beauty premium and highlight the boundary conditions for its existence. We also contribute to the nascent research on ICOs, which thoroughly investigates the determinants of ICO success and post-ICO performance (e.g., Fisch, 2019; Howell et al., 2020; Momtaz, 2020a, 2021a), but is silent about the existence of a founder CEO beauty premium in ICOs. Relatedly, our study extends its importance to the broadening field of digital finance (Kolbe, Mansouri, \& Momtaz, 2021), where visual cues could deliver important insights into how investors make decisions.

\section{2 | INSTITUTIONAL BACKGROUND: INITIAL COIN OFFERINGS}

\subsection{Description of ICOs and the ICO market}

We assess the effect of founder CEO attractiveness on firm valuation in the context of ICOs, one of the latest developments in entrepreneurial finance. In an ICO, a firm raises funds by selling tokens online to a crowd of investors (Fisch, 2019). Tokens are cryptographically protected digital units of value that provide utility or security functions to investors (Gan, Tsoukalas, \& Netessine, 2021; Howell et al., 2020; Momtaz, 2021a). For example, tokens can be used to purchase a product or service in the future, thus resembling traditional vouchers (utility function). Tokens can also function as a medium of exchange among users on the ICO venture's platform. Additionally, tokens can resemble traditional securities and entitle the token holder to a share of the venture's (future) profits, ownership, or other financial benefits (security function).

A particularity of ICOs is that blockchain technology serves as the processing platform, enabling a direct and immediate transaction between ICO investors and ICO ventures. Blockchain technology is a novel approach to recording and transmitting data across a network in an immutable manner, using cryptographic proof (Chen, Pereira, \& Patel, 2021; Yermack, 2017). Therefore, ICO firms are typically young firms in the blockchain sector that work on technologically demanding projects so that ICOs represent a crucial channel for funding highly innovative blockchain ventures (Fisch, 2019; Gan et al., 2021). Due to the importance of blockchain technology for future innovation, the support and financing of highly innovative projects in the blockchain sector is a key issue for policymakers. 
The market for ICOs is novel, dynamic, and nontrivial. Bellavitis, Fisch, and Wiklund (2021) provide a detailed account of the development of ICOs and show that the number of ICOs and the funding raised is considerable, despite the phenomenon's recency. While the first ICO was conducted in 2013, meaningful ICO activity commenced in 2017, in which 952 ventures raised approximately $\$ 7.5 \mathrm{~b}$ (i.e., $\$ 7.9 \mathrm{~m}$ per ICO). In 2018, the ICO market reached its current peak, with 2,598 ICO raising a combined \$12.3b. In light of the overall cooldown of the blockchain sector since 2019, funding volumes have declined since then. Despite its brief history, the funding raised in ICOs already surpasses the volume raised in crowdfunding (Bellavitis et al., 2021).

The mean funding per ICO ranges between $\$ 10$ and $\$ 20 \mathrm{~m}$, and median funding values range between $\$ 5$ and $\$ 10$ m (Bellavitis et al., 2021; Howell et al., 2020; Momtaz, 2020b). However, there is considerable heterogeneity in the funding raised in ICOs: While some ICOs raise in the five-figure range, the largest ICOs raise billions (e.g., EOS raised over \$4b) and thus compete with large VC financing rounds or initial public offerings (IPOs).

\section{2 | Characteristics of ICOs}

The reasons for the increasing prominence of ICOs are multifold. ICOs do not require intermediaries. Due to blockchain technology's disintermediated nature, the funds are directly transferred from ICO investors to ICO ventures. This minimizes transaction costs in terms of time and money (Bellavitis, Cumming, \& Vanacker, 2020; Fisch, 2019; Momtaz, 2021a). Due to their novelty, ICOs are also relatively unregulated (e.g., Howell et al., 2020). In contrast to other capital-raising processes, the absence of intermediaries and a comparatively low degree of regulation make ICOs relatively effortless and unbureaucratic to set up and execute (Gan et al., 2021). Finally, blockchain technology's digital and scalable nature allows ventures to raise capital from a large crowd of investors with few geographical restrictions (Bellavitis et al., 2021).

However, ICOs are discussed controversially because they involve a high degree of uncertainty, making them a volatile and risky investment. Uncertainty is high because ICO ventures are typically in the very early stages when conducting an ICO, which makes it difficult to assess the venture's underlying quality (Momtaz, 2020b). Here, their products or business models are not fully developed, so that the tokens sold often refer to a future good or service, or future profits that the venture may or may not realize (Howell et al., 2020). In addition to the venture's prospects being uncertain, the future development and adoption of blockchain technology, which most ICO ventures build on, is uncertain (Fisch, 2019). Also, because ICOs are only loosely regulated in most jurisdictions and because litigation is difficult, the risk of malignant behavior (e.g., fraud, scams) is higher than in other forms of finance (Cole, Johan, \& Schweizer, 2021; Corbet \& Cumming, 2020; Cumming, Hornuf, Karami, \& Schweizer, 2020). The prevalence of fraudulent ICOs prompted multiple regulators (e.g., in the US and Germany) to issue formal investor warnings, while other jurisdictions outright banned ICOs (Bellavitis et al., 2020). Finally, uncertainty is increased due to the absence of intermediaries, which often enforce disclosure requirements in a market and reduce the information asymmetry between investors and ventures (Boreiko \& Risteski, 2021; Momtaz, 2020b). The absence of intermediaries and disclosure requirements in ICOs also leads to a situation in which little information is available to ICO investors because these investors have to rely solely on the information released by the ICO venture (Fisch, 2019).

\subsection{Characteristics of ICO investors}

So far, little systematic knowledge on ICO investors exists. In contrast to more traditional entrepreneurial finance channels, investors in ICOs enjoy a high degree of anonymity. The desire to enable anonymous transactions is one of the ideological and technological cornerstones of blockchain technology (Fisch, Masiak, Vismara, \& Block, 2021). More specifically, ICOs are generally pseudonymous: while it is possible to trace back the origin of an ICO investment to a certain account, the account holder's identity remains unknown (Kastelein, 2017). This pseudonymity 
makes information on ICO investors scarce. For example, ICO ventures often do not know who their investors are and have no way of personally contacting them. This also has implications for ICO research, which lacks systematic data that could enable a comprehensive understanding of ICO investors.

Against this backdrop, Fisch et al. (2021) perform a survey of 517 ICO investors to identify characteristics and investment motives. The authors find that ICO investors pursue financial, technological, and ideological motives in their investments. Technological motives are considered more important than financial and ideological motives. However, selling tokens at a higher price after the ICO's conclusion, a financial motive, is the single most important reason that ICO investors gave.

This financial rationale is closely related to another distinguishing feature of ICOs that is attractive to investors: after the ICO's conclusion, tokens can be traded in a secondary market. This secondary market trading resembles the trading of traditional stocks after an IPO (Fisch \& Momtaz, 2020; Mansouri \& Momtaz, 2021; Momtaz, 2021c). This also adds speculative function to ICO investments, since ICO investors sometimes buy tokens that they think will appreciate in value without any intention of ever using the venture's products (Gan et al., 2021). Because tokens' aftermarket prices are highly volatile (Drobetz, Momtaz, \& Schröder, 2019; Lyandres et al., 2019), such investments attract investors with a high risk-return profile (Fisch et al., 2021; Howell et al., 2020).

Finally, most ICOs are financed by a high number of small investments from a large crowd of ICO investors. For example, Fahlenbrach and Frattaroli (2021) show that their sampled ICOs each attracted 4,700 investors that contributed $\$ 1,500$, on average. Similarly, Boreiko and Risteski (2021) use a different sample of ICOs and report an average of 1,600 investors that contributed $\$ 5,625$ per ICO. Both studies leverage publicly available data on the blockchain to derive these conclusions. While both studies are unable to provide more information on ICO investors due to the investor's pseudonymity, they conclude that the number of investors and the amount invested in ICOs is substantially larger than in crowdfunding. Fahlenbrach and Frattaroli (2021) also conclude that ICO investors invest substantially less than accredited investors that would participate in angel or VC rounds. This data is in line with prior ICO research, which often assumes ICO investors to be small and unsophisticated retail investors (Bellavitis et al., 2020; Benedetti \& Kostovetsky, 2021; Fisch \& Momtaz, 2020).

\section{3 | CONCEPTUAL BACKGROUND AND HYPOTHESES}

The characteristics outlined in the previous section make the valuation of ICO firms and the prediction of their performance challenging. The typical ICO firm has no track record, its business model is often untested, and the bulk of ICO investors consist of financially motivated retail investors. These characteristics likely increase the importance of the CEO, who typically is one of the firm's founders, as an indicator of firm quality. This makes ICOs an ideal context to empirically explore the relationship between founder CEOs' attractiveness and firm valuation. In this section, we review existing research on the beauty premium in related disciplines and derive hypotheses on the role of CEO attractiveness in ICOs.

\subsection{Conceptual background: The beauty premium}

Studies in disciplines as different as social psychology, labor economics, finance, and strategy highlight the existence of a positive association between individual attractiveness and success. For example, since the seminal paper by Hamermesh and Biddle (1994), research in labor economics has documented the existence of a "beauty premium." Previous studies find that attractive candidates are more often and sooner contacted for job interviews and are more likely to gain employment and receive higher ratings (Barrick, Shaffer, \& DeGrassi, 2009; Eagly, Ashmore, Makhijani, \& Longo, 1991), especially if they are male (López Bóo, Rossi, \& Urzua, 2013; Ruffle \& Shtudiner, 2015). Attractive candidates are also able to negotiate higher wages (Mobius \& Rosenblat, 2006) and make more rapid 
career progressions (Biddle \& Hamermesh, 1998; Hamermesh, 2011). A more favorable treatment of attractive individuals also occurs in other spheres of activity, such as education (Cipriani \& Zago, 2011), politics (Berggren et al., 2010), and charitable giving (Jenq, Pan, \& Theseira, 2015; Park, Kim, \& Hong, 2019).

While the existence of a beauty premium is undisputed, there is little consensus about its causes. A first explanation stems from social psychology and attributes the premium to peoples' positive stereotypical biases in favor of attractive individuals (for a review, see Maestripieri et al., 2017). Individuals are inclined to interpret physical traits as proxies for unobserved attributes that correlate with positive behavioral characteristics, such as competence or trustworthiness. Thus, they judge and treat more attractive individuals more favorably than less attractive ones. The finding that "what is beautiful is good" dates back to the pioneering work of Dion et al. (1972). Since then, the existence of stereotypical biases has been readily explored and coherently summarized in several meta-analyses (e.g., Feingold, 1992; Langlois et al., 2000; Rhodes, 2006).

A second explanation is rooted in the theory of "statistical discrimination" (Arrow, 1973; Phelps, 1972) and assumes that fully rational economic agents have imperfect information on individuals' abilities and therefore rely on statistical information to infer these abilities, including information on individuals' attractiveness. For example, studies of the labor market argue that more attractive employees receive preferential treatment in the labor market because they generate, on average, productivity gains for employers. Reasons for the proposed productivity boost include that consumers' utility may increase if they interact with more attractive individuals, thereby increasing demand for the products of the firms that employ them. This bias in favor of attractive people may also become a self-fulfilling prophecy: more attractive individuals receive greater attention and preferential treatment from parents and teachers from their childhood (Langlois et al., 2000). Thus, they develop superior skills over time, such as social skills, which are useful in negotiating and communicating with third parties. This ultimately translates into a positive productivity effect (Biddle \& Hamermesh, 1998). ${ }^{1}$

Prior research assesses the relative merits of the different arguments empirically, with mixed results. In line with the view that more attractive individuals are more productive, Biddle and Hamermesh (1998) show that privatesector lawyers are more attractive than those in the public sector, and specialize in tasks for which social skills are more valuable. Physical appearance per se partly explains the results of Cao, Guan, Li, and Yang (2020), who link the more accurate earnings forecasts of more attractive financial analysts to the fact that they receive more internal support from their employers, gain more media exposure, and have easier access to firm managers for information than less attractive analysts. Regarding stereotype-based biases, Mobius and Rosenblat's (2006) experiment abstracts from any productivity effect and shows that more attractive individuals are more self-confident, which has a positive impact on employers' perception of their ability. The stereotypical beliefs of employers that operate through both oral and visual interactions with candidate employees "make the beautiful appear more able in the eyes of employers" (Mobius \& Rosenblat, 2006, p. 15).

Moving closer to the domain of our study, a few studies investigate the allegedly positive role of individuals' physical attractiveness in securing funds and in being appointed as CEOs. Again, they generally document a positive association (with some exceptions), but their results give divergent indications about the underlying theoretical mechanisms. Regarding fundraising, Price (2008) shows that more attractive female solicitors elicit greater contributions from donors and that this effect is stronger for blonde females than brunette ones. Relatedly, Ravina (2019) finds that attractive borrowers using a peer-to-peer lending platform are $11.7 \%$ more likely to successfully apply for loans, pay similar interest rates as average-looking borrowers with the same credentials, and default more often. However, the evidence of a positive role of borrowers' attractiveness in peer-to-peer lending transactions is not supported by Duarte, Siegel, and Young (2012). Blankespoor, Hendricks, and Miller (2017) focus on IPOs and find a positive relation between the attractiveness of IPO firms' CEOs and the market value of firms' common equity calculated using the proposed offer price, the final offer price, and the stock price at the end of the first day of trading in the secondary market, respectively.

Other studies that consider the physical appearance of CEOs provide inconclusive results. Some studies (e.g., Graham, Harvey, \& Puri, 2017; Stoker, Garretsen, \& Spreeuwers, 2016) find that the facial appearance of CEOs is 
different from that of other individuals but that their attractiveness is not related to firm performance. Conversely, other studies in addition to Blankespoor et al. (2017) do provide evidence consistent with the existence of a CEO beauty premium. Cook and Mobbs (2019) show that candidate CEOs' facial attractiveness positively influences board directors in their CEO selection decisions. CEOs' attractiveness also relates positively to their compensation and the likelihood of their appointment as chairman within 6 months of their selection as the new CEO. Lastly, their findings indicate that shareholders react more favorably to the appointment of more attractive CEOs. Halford and Hsu (2020) similarly provide evidence supporting the view that firms led by more attractive CEOs are more valuable. They find that firms' abnormal stock market returns around CEOs' hiring announcements are more positive for more attractive CEOs. They also highlight that the attractiveness of acquirers' CEOs is positively related to acquirers' abnormal returns around the acquisition announcement date and that stock market investors react more positively to television news and earning announcement news containing the CEOs' pictures if the CEOs are more attractive. Nevertheless, CEO attractiveness may have a dark side. Connelly, Lee, Hersel, and Walker (2020) show that when firms are found guilty of misconduct, attractive CEOs are more likely to be fired by boards than their less attractive peers.

Very few studies examine the role of attractiveness within the context of entrepreneurship. Baron et al. (2006) investigate whether more attractive entrepreneurs enjoy an advantage in starting and running their ventures. They conduct three empirical studies. Findings from Study 1 indicate that more attractive entrepreneurs are rated as showing more positive traits and as having a higher commitment and greater social skills. Their ideas for new products are also rated more favorably. These positive effects are mediated by the positive affect generated among raters. In Study 2 , entrepreneurs and their business ideas were rated by persons who watched them while they were making presentations to potential investors. Again, their rating was positively associated with their attractiveness, which was independently rated by other judges. Lastly, Study 3 provides evidence supporting the view that the more favorable perception of more attractive entrepreneurs contributes to their success. In fact, (female) entrepreneurs working in the cosmetics industry that were rated as more attractive also had substantially higher income than their less attractive peers. More recently, Patel \& Wolfe, 2019 conduct two empirical studies to explore the association between individuals' attractiveness, the probability that these individuals are self-employed, and their income as self-employed people. In Study 1 , they find that males are more likely to be self-employed when they are more attractive. Moreover, they detect a positive association between individuals' income and attractiveness, which is steeper for self-employed individuals. Conversely, results are not significant for females. The findings of Study 2 show that self-employed males are perceived as more attractive than twin-salaried males. They also indicate that the positive association between attractiveness and income is more pronounced for self-employed males with lower IQs. Again, results for females are inconclusive.

To the best of our knowledge, Brooks et al. (2014) and Davila and Guasch (2020) are the only studies concerned with the effect of entrepreneurs' physical attractiveness on fundraising. Brooks et al. (2014) consider pitches presented to a panel of angel investor judges at three entrepreneurial pitch competitions in the United States. Attractive male entrepreneurs are considerably more likely to achieve pitch competition success than less attractive male entrepreneurs. Differences between more and less attractive female entrepreneurs were not significant. Davila and Guasch (2020) manipulate videos of entrepreneurs presenting their firms to an audience of investors. Entrepreneurs' attractiveness, judged by a set of independent raters, is positively related to the likelihood of receiving finance from professional investors. However, firms led by more attractive entrepreneurs do not perform differently from other firms in terms of survival and growth.

In sum, while the few previous studies on this topic suggest that entrepreneurs do enjoy a beauty premium in obtaining external finance, they are uninformative about its economic magnitude and the underlying mechanisms that explain it.

\section{2 | Hypotheses}

ICOs offer an ideal context in which to identify a potential founder CEO beauty premium for at least two reasons. First, firms are typically in their very early stages when conducting an ICO (Chen et al., 2021; Fisch, 2019; Howell 
et al., 2020). In these early stages, founder CEO attributes are first-order determinants of firm performance. This is because the strategic decisions taken by founder CEOs in early-stage ventures are particularly crucial for the ventures' development and eventual success (Chatterji, Delecourt, Hasan, \& Koning, 2019; Colombo \& Grilli, 2005; Kulchina, 2017). Second, ICOs happen in a legal "gray zone" characterized by a scarcity of information (Fisch, 2019). Reasons for the large information asymmetry between investors and investees include a lack of effective institutions (Momtaz, 2020b) and established intermediaries (Fisch \& Momtaz, 2020), and limited availability of reliable information. Indeed, many ICO firms have no track record and may exaggerate their qualities in white papers (Momtaz, 2020b). Thus, investors are forced to rely on noisy indicators of ICO firms' quality in their investment decisions.

Following these arguments, the limited existing empirical evidence shows the prominent impact of the ventures' human capital endowment on firm valuations in ICOs, and that of the founder CEO specifically. For example, prior studies show that ICO valuations are related to traditional human capital characteristics, such as team size (Lyandres et al., 2019), expert ratings of the management team (Momtaz, 2020a), Linkedln connections (Campino, Brochado, \& Rosa, 2021), founder CEO age and education (Momtaz, 2021a), and founders' industry backgrounds (An et al., 2019). This research also considers less traditional human capital characteristics. Momtaz (2020c) finds that loyalty toward the founder CEOs' previous employers is positively related to ICO firm valuations. Other studies point to the influence of founder CEOs' facial expressions on firm valuation (Huang, Vismara, \& Wei, 2021; Momtaz, 2021a), as well as to founder CEOs' language used in video pitches (Kolbe et al., 2021) and their emotions (Momtaz, 2021a, 2021d).

Against this background, we argue that founder CEO attractiveness is an important piece of information that ICO investors consider when making investment decisions. There are two different conceptual explanations for a positive association between founder CEO attractiveness and firm valuation. Following the statistical discrimination argument (see also Arrow, 1998), in absence of more reliable indicators of firms' quality, ICO investors recognize that firms led by more attractive founder CEOs are more likely to be more productive because of their CEOs' superior managerial abilities, most notably related to their social skills. Hence, investors are more inclined to invest in firms led by these founder CEOs, and these firms will enjoy more favorable ICO valuations.

Based on the arguments above, we derive hypothesis $\mathrm{H} 1$, which predicts a positive association between founder CEO attractiveness and ICO firm valuations. ${ }^{2}$

Hypothesis 1 (H1). Founder CEO attractiveness is positively related to ICO firm valuation.

In deriving $\mathrm{H} 1$, we emphasize that the lack of information and the pronounced information asymmetry in ICOs are reasons for the existence of a positive, direct association between founder CEO attractiveness and the valuation of their firms in ICOs. This relationship should be weaker if additional information exists that ICO investors consider more reliable than founder CEO attractiveness.

Prior ICO research documents that firm valuation in ICOs is influenced by current market sentiment (e.g., Drobetz et al., 2019; Howell et al., 2020; Momtaz, 2020b). A possible reason is that market-related sentiment is perceived as the "wisdom of the crowd" in the absence of more reliable information and the ability to interpret it (Drobetz et al., 2019). The importance of market sentiment is also reflected in the high volatility of the cryptocurrency markets (of which ICOs are a part), which is characterized by cycles of extensive hype that lead to increased firm valuations (Chaim \& Laurini, 2018; Howell et al., 2020).

In addition to market-related sentiment, sentiment can be firm-specific. In particular, ICO firms frequently try to create positive sentiment among investors to solicit investments. Indeed, prior research shows a positive association between firms' activity on social media platforms (e.g., Twitter, Telegram) and their ICO valuations (Fisch, 2019; Howell et al., 2020; Momtaz, 2020a). These channels enable direct communication between firms and potential ICO investors, which firms can use to create positive sentiment among investors. Another vital tool in ICO firms' communication strategies, which has been associated with increased ICO success, is the white paper, which is a prospectus that provides information on the ICO firm to the public. 
In summary, it seems that ICO investors are positively swayed by positive market-related and firm-related sentiments. Therefore, when market-related sentiment and firm-related sentiment are positive, ICO investors are less sensitive to supposedly noisier information being channeled to them by ICO firms; notably, information on the attractiveness of their founder CEOs. Under these conditions, the positive relationship between founder CEO attractiveness and firm valuation becomes weaker.

Hypothesis 2a ( $\mathrm{H} 2 \mathrm{a})$. The relationship between founder CEO attractiveness and ICO firm valuation is negatively moderated by positive market-related sentiment.

Hypothesis $2 \mathrm{~b}(\mathrm{H} 2 \mathrm{~b})$. The relationship between founder CEO attractiveness and ICO firm valuation is negatively moderated by positive firm-related sentiment.

Finally, public offerings provide a natural setting in which to investigate firms' financing decisions in which asymmetric information is a base for corporate misvaluation. The windows-of-opportunities theory argues that firms benefit from periods during which investors are optimistic about the future of an industry by timing their offering and obtaining higher valuations (Loughran \& Ritter, 1995). Accordingly, evidence of the long-run underperformance of firms issuing equity is well-documented (e.g., Ritter, 1991; Schultz, 2003). Empirical evidence primarily comes from studies on IPOs in traditional stock markets. Instead, no secondary market prices are observable for traditional entrepreneurial finance markets, such as the venture capital market, in which transactions largely occur behind closed doors. The unique context of ICOs allows for founder CEO attractiveness to be related to post-financing firm performance on a daily basis, by using readily observable daily prices for each cryptocurrency token that is exchangetraded. ICOs are indeed public events and all financial transactions during the ICO and afterward are contained in blockchain data; hence, also publicly available. Since tokens are listed shortly after the ICO ends, investors have both the opportunity to directly and "disintermediately" invest in an ICO firm as well as the possibility to easily divest.

The availability of measures related to the post-financing performance of ICO firms allows for a test as to whether the decisions agents make during an ICO are "right." In this context, "actions" (investments) are "right" as far as they are consistent with the goals of the actors (investors). For investors, returns are the relevant performance measure. If firms led by more attractive founder CEOs enjoy higher valuations at ICO because of the superior managerial abilities of their CEOs, these firms should subsequently outperform their peers in the post-ICO period. If, on the contrary, the attractiveness of founder CEOs is not related to the firms' quality, the firms' higher ICO valuations will mean-revert over time. These firms may still receive greater valuations at the time of their ICOs, especially if investors have positive stereotypical biases toward attractive founder CEOs, but will exhibit underperformance in the aftermarket. As market enthusiasm starts to fade, the prices of tokens are progressively downward adjusted over time, resulting in negative post-ICO performance.

Hypothesis $3(\mathrm{H} 3)$. Founder CEO attractiveness is positively related to firms' post-ICO performance.

\section{I SAMPLE AND DATA}

\section{1 | Main survey (Survey 1) to collect data on founder CEO attractiveness}

Prior empirical research on attractiveness typically proceeds without a specific definition of attractiveness. Instead, most empirical studies are survey-based and require respondents to rate the attractiveness of the individuals under investigation. This attractiveness measurement builds on a long tradition of research in social psychology, which documents a considerable agreement on perceptions of attractiveness among individuals, which is stable within and across cultures (Langlois et al., 2000). The use of survey-based measures of attractiveness is common in political 
sciences (Berggren et al., 2010), economics (Graham et al., 2017), and finance (Duarte et al., 2012). Mimicking the surveys used in these studies, we collect data on founder CEO attractiveness via three distinct surveys. The main survey is described below, while the other two surveys are described in detail in Section 5.3.

We initially collected a comprehensive sample of photos of ICO firms' founder CEOs, which were later assessed in terms of their attractiveness by our survey respondents. The population of ICOs listed on ICObench (www.icobench.com) was retrieved in April 2019. ICObench is the most comprehensive aggregator of information on ICOs and is a frequently used data source in ICO research (e.g., Lyandres et al., 2019; Momtaz, 2020a, 2020b). This sample of ICOs was supplemented with information from other ICO aggregators, such as ICOalert, ICOdrops, and CoinSchedule. The information provided by such ICO aggregators typically includes a picture of the firm's CEO. Importantly, these ICO aggregators are also used by actual investors when investigating ICOs (Fisch et al., 2021). Hence, these CEO pictures are the same pictures that ICO investors can access during their investment process. In a small number of cases, no photo was available from the aggregator websites. In these cases, the CEO's image was manually researched on the ICO firm's website or Linkedln. ${ }^{3}$ ICO firms for which a picture could not be identified were discarded ( $<5 \%$ of the sampled firms). ${ }^{4}$ In total, the sample comprises 4,092 CEO pictures. To address a critical endogeneity concern, we only considered those CEOs that were also founders of the company (i.e., they were not hired later on) (Howard, Kolb, \& Sy, 2021; Kumar, Nagarajan, \& Schlingemann, 2020).

A web-based survey was then constructed, based on these pictures. To solicit participants, more than 3,000 individuals who identified themselves as ICO investors were contacted on Twitter and/or Linkedln. The survey targeted ICO investors to ensure a high degree of theory-measurement alignment. They were informed of the study and about the intention to measure the attractiveness of CEOs but were not given any other information, either about the CEO or the ICO. As a reward for participation, early access to the study's results was promised to the respondents.

In the survey, respondents were presented with the full list of 4,092 ICOs. Investors were asked to select those ICOs in which they had previously invested, based on the ICO firm's name. For each selected ICO, the respondent was then shown a $5 \times 3.5 \mathrm{~cm}(2 \times 1.4 \mathrm{in}$.) photo of the firm's CEO and was asked to rate the attractiveness of each CEO on a scale from 1 (very unattractive) to 10 (very attractive). Respondents that had invested in multiple ICOs were asked to rate multiple CEOs. Only CEOs who had been rated by at least three investors were considered, to ensure a higher validity and robustness of the attractiveness ratings. This restriction led to a final sample of 4,452 CEO attractiveness ratings pertaining to 740 CEOs, by 633 ICO investors. ${ }^{5}$ The range of assessments per investor is one to $43 .^{6}$

The CEO attractiveness data are supplemented with data obtained from ICObench and other ICO aggregators (ICOalert, ICOdrops, and CoinSchedule). This data includes information on ICO firms' valuations, ICO campaign characteristics, and the names of firms' team members. In the case of missing data, ICO firms' websites and white papers were scrutinized. Additionally, every CEO, and all of the firm's team members, were manually researched on LinkedIn. Multiple individual-level variables were constructed, based on information from Linkedln, such as the CEO's level of formal education and the aggregated work experience of the venture team. Other data sources include CoinMarketCap, GitHub, and CryptoFundResearch.

\section{2 | Variables}

The main dependent variable is the ICO firm valuation [firm valuation (log.)], measured via the (log of the) amount of funding raised in the ICO (in \$m). Funding raised is the most prevalent proxy of ICO success in prior research (Fisch, 2019; Momtaz, 2020a; Philippi, Schuhmacher, \& Bastian, 2021) and is commonly used as a proxy of ICO firm valuation (Momtaz, 2021a). The variable is included in logged form to account for its skewness. The data is obtained from ICO aggregators. 
Post-ICO performance is measured via buy-and-hold arithmetic returns (BHARs). BHARs quantify investor returns over the first 6 months following the first trading day. Following Momtaz (2021b), the price data comes from CoinMarketCap, which is the premier source of information on the trading of ICO tokens (Lyandres et al., 2019; Momtaz, 2021b).

The independent variable is CEO attractiveness (CEO attractiveness). As described earlier, the attractiveness data is collected via a web-based survey in which ICO investors rated the attractiveness of firms' CEOs on a scale from 1 (very unattractive) to 10 (very attractive). The variable is calculated as the median of all available investor ratings for every CEO with more than three ratings. We z-standardize our founder CEO attractiveness measure (i.e., mean $=0$, standard deviation $=1$ ) to ease the coefficients' interpretability. ${ }^{7}$

The moderators capture firm-related and market-related sentiment. To measure firm-related sentiment, a Natural Language Processing (NLP) approach is applied to ICO firms' white papers to extract the polarity of expressed opinion (Drobetz et al., 2019). We use a QDAP dictionary to quantify the sentiment of each word in the white paper, which is then weighted in the presence of amplifier words or negations (e.g., "very intelligent" has a higher positive sentiment score than "intelligent"). The overall sentiment score for a white paper is computed as the sum of all terms that express sentiment and is ultimately normalized by the number of words in the white paper. The measure scales from -1 to +1 and a higher polarity score signifies a more positive sentiment. The results are robust when other dictionaries s are used (Harvard IV, Loughran-McDonald).

To measure market-related sentiment, Thomson Reuters' MarketPsych index is used, which measures sentiment for the entire crypto market (i.e., ICOs and cryptocurrencies in general). The index is constructed daily, via a lexical analysis obtained from more than 2,000 news sources included in LexisNexis, and 800 social media platforms (Twitter, Reddit, etc.). Specifically, the "buzz index" is used, which measures the expression intensity. We assume that a high level of "buzz" indicates more positive sentiment. The index is publicly available, has been used in prior ICO research, and is considered as a good proxy for market sentiment (Drobetz et al., 2019).

Lastly, to rule out confounding explanations, a rich set of control variables is included, in line with prior ICO research (Fisch, 2019; Howell et al., 2020; Momtaz, 2020b). The first set of control variables refers to CEO characteristics, which might distort how investors perceive the attractiveness of CEOs, and which might be related to firm valuation. As suggested in prior research, these characteristics include age, gender, and race (Graham et al., 2017). For example, younger or older CEOs might be perceived as more attractive to some investors. Thus, two dummy variables are created, which capture whether the CEO is young (i.e., <30 years old) or old (i.e., >40 years old). We also control for the CEOs' gender (female) and race (Asian or Black, with White as the base group).

The second set of controls includes team characteristics. Larger amounts of teams' human and social capital are associated with an increased probability of ICO success (Howell et al., 2020; Lyandres et al., 2019; Momtaz, 2020a). We include the fraction of team members with PhD or Master's degrees, as well as the number of team members with a business degree or with a technical degree in addition to the firm's team size (i.e., the number of team members at the beginning of the ICO), ${ }^{8}$ as well as the team's aggregate work experience. Our study distinguishes between general professional experience and more specific crypto experience, which captures work experience related to ICOs and the crypto sector. Both, general professional experience and crypto experience are expressed in the number of years and scaled by team size. To account for the teams' social capital, we consider the number of the focal firm's ICO advisors (\# advisors). Also, the number of contacts of the firm's team members is measured on Linkedln, the largest social network in the professional sphere [\# Linkedln contacts (log.)]. Information on the team members is obtained from ICO aggregators and supplemented with data from Linkedln.

The third set of controls include ICO characteristics. We control for the ICO firm's age, whether the ICO firm uses ICO-related promotion tools such as a pre-ICO, in which early investors can buy a limited number of discounted tokens (pre-ICO), or a reward program (i.e., bounty programs), in which ICO investors receive rewards (free tokens, discounts) for promoting the ICO (bounty) (Fisch \& Momtaz, 2020; Howell et al., 2020). We also include a variable that captures the ICO's duration in days (ICO duration) (Fisch, 2019), the number of competing ICOs, and the overall ICO rating by ICObench (Bellavitis et al., 2020). ICOs frequently implement Know-Your-Customer (KYC) processes 
that bar unregistered investors from participating in the ICO, which could negatively impact the funding raised because the pool of potential investors is reduced (Fisch \& Momtaz, 2020). Hence, we include a dummy variable, which captures whether a KYC policy is in place $(K Y C)$. A further dummy variable is included, which captures whether the venture makes its source code freely available online on GitHub (open source). Having open-source code has been described as a signal of technological capabilities, which is related to ICO success (Fisch, 2019; Howell et al., 2020; Philippi et al., 2021). Furthermore, we control for whether the ICO firm operates on an already-existing blockchain standard, such as Ethereum, or whether the ICO develops a proprietary blockchain (existing blockchain). The advantages of using a preexisting blockchain typically include greater interoperability, a more advanced infrastructure, and access to network externalities (Fisch \& Momtaz, 2020). Another variable that has been associated with firm valuation in ICOs is token supply [token supply (log.)], which measures the number of tokens offered to investors. ICOs can impose trading restrictions on their tokens after the ICO. During this lock-up period, investors cannot sell the tokens they acquired in ICOs. The limitation on exit options and liquidity might deter some ICO investors and impact firm valuation. The dummy variable takes a value of one if a token lock-up is in place, and zero otherwise (lock-up). Finally, we include time dummies, industry dummies, and country dummies.

Table 1 shows summary statistics and pairwise correlations between the variables (for variable definitions and data sources, see Table A1 in the Appendix). The summary statistics are comparable to other ICO studies (e.g., Fisch, 2019; Howell et al., 2020; Huang et al., 2021; Momtaz, 2020b). In particular, the founder CEO of $44 \%$ of the ICO firms in our sample is less than 30 years old, while only $6 \%$ of the founder CEOs are more than 40 years old. Male founder CEOs account for $93 \%$ of the sample. As for ethnicity, Asian founder CEOs are more represented than black CEOs (26 vs. $3 \%$, respectively). The average ICO includes 10.61 team members and 4.68 advisors. The correlations indicate that multicollinearity should not bias the results in a meaningful way. We also check Variance Inflation Factors (VIFs) and find in untabulated results that all VIFs are well below the commonly agreed-upon threshold of 5 (Leitterstorf \& Rau, 2014).

\section{5 | EMPIRICAL RESULTS}

\section{1 | Main results}

Table 2 shows regression results for the main model in column (2). To demonstrate that the CEO attractiveness-firm valuation relationship is not driven by the presence of our control variables, column (1) presents a control model, excluding only the measure of founder CEO attractiveness. The main model in column (2) indicates that firm valuation is an increasing function of CEO attractiveness. The coefficient for founder CEO attractiveness (0.1236) is statistically significant $(p<.05)$. To ease the economic interpretation of the results, our measure of CEO attractiveness is $z-$ standardized (mean $=0$, standard deviation $=1$ ). A 1-SD increase in founder CEO attractiveness is associated with a $13.2 \%[=\exp (0.1236)-1]$ increase in firm valuation. For the hypothetical scenario in which two identical, average firms would conduct an ICO with founder CEOs who only differed in their perceived attractiveness by 1-SD, the more attractive founder CEO would increase firm valuation by $\$ 1.58 \mathrm{~m}$. Given the average firm valuation of $\$ 11.99 \mathrm{~m}$, our estimated marginal effect is economically meaningful.

Several additional econometric approaches assess the robustness of the main result. First, to rule out that outliers are driving our results, we resort to a dummy variable approach, in which founder CEO attractiveness takes the value of 1 if the founder CEO's attractiveness is rated above the sample median, and 0 otherwise. The results in column (3) show that the effect is (weakly) statistically significant $(p<.1)$. Second, two distinct two-stage approaches are employed to address concerns about potential unobserved heterogeneity. This would be an issue if more valuable firms were more likely to appoint more attractive founder CEOs for whatever reason. In the first approach, we re-run the main model with a Propensity Score-Matched (PSM) sample. The propensity score is derived from the first stage that predicts CEO attractiveness based on other characteristics of founder CEOs and their firms, which is 


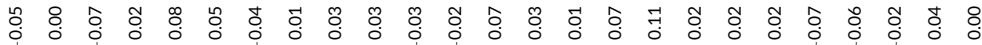
శิ

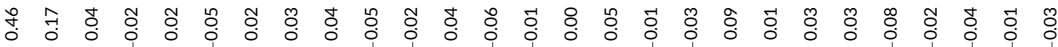
웡 궁 总

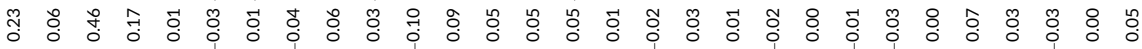

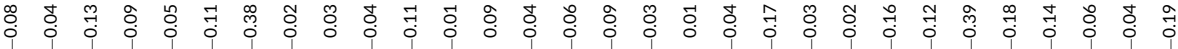

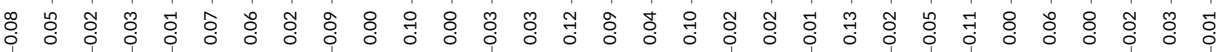
赵

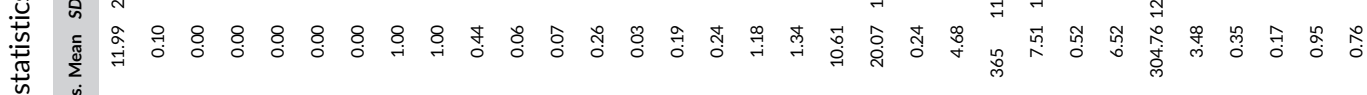

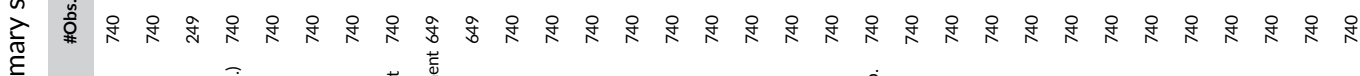




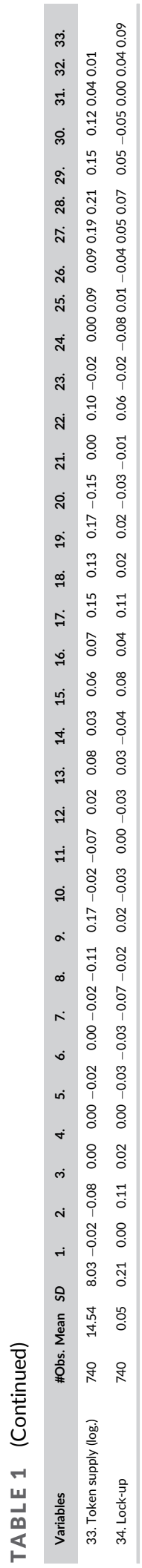


reported in column (4). A one-to-one nearest-neighbor matching algorithm is employed without replacement. ${ }^{9}$ The regression results with the PSM sample are shown in column (5). The results underline the robustness of the main results. The other approach is based on conditioning on the inverse Mills ratio (IMR) in column (6). This helps to control for heterogeneity within the PSM sample. The regression results indicate that the CEO attractiveness-firm valuation relation is not driven by unobserved heterogeneity. The regression coefficients on CEO attractiveness are relatively similar in magnitude to our main model [0.1226 in column (5) and 0.1224 in column (6)], and statistically significant $(p<.05)$. Altogether, the evidence provides support for $\mathrm{H} 1$; that is, there appears to be a pronounced founder CEO beauty premium in ICOs. Lastly, we also experimented with including the second polynomial term for CEO attractiveness to test for a potential curvilinear effect but found statistically non-significant results (available from the authors upon request).

For the control variables, largely consistent parameter estimates are found throughout all model specifications. In particular, team size, the size of the social network, and the ICO expert rating positively relate to firm valuation, while relatively young founder CEOs are negatively related to firm valuation. The same holds for the existing blockchain variable, possibly indicating that firms that do not leverage existing blockchain technologies are perceived as more innovative by ICO investors. In line with existing studies on the role of human capital in ICOs, we find that human capital characteristics of the CEO as well as the overall team are not statistically significant (with the aforementioned exceptions of young age, team size, and Linkedln contacts; An et al., 2019; Campino et al., 2021).

$\mathrm{H} 2$ posits that the founder $\mathrm{CEO}$ beauty premium is moderated by firm-related and market-related sentiment. To test $\mathrm{H} 2$, we insert in the main model the variables firm-related sentiment and market-related sentiment, and their interaction terms with founder CEO attractiveness. Table 3 shows the regression results in column (1). Founder CEO attractiveness, firm-related sentiment, and market-related sentiment are all individually significantly positive. The interactions of founder CEO attractiveness are significantly negative, suggesting that the positive association between founder CEO attractiveness and firm valuation weakens in the presence of more positive sentiment. These results suggest that the size of the CEO beauty premium depends on investors' information sets, in that investors rely more on CEO attractiveness as an indicator of firm value when they have a more limited information set. ${ }^{10}$ In untabulated analyses, we confirm that the results illustrated above hold if we perform the two-stage analyses with the PSM sample and with additional IMR conditioning. Overall, the findings lend strong support to $\mathrm{H} 2 \mathrm{a}$ and $\mathrm{H} 2 \mathrm{~b}$.

Finally, to assess the relationship between CEO attractiveness and post-ICO firm performance (H3), BHAR are computed for holding periods of 6 months after the initial listing date. We estimate the main model, but with BHAR as the dependent variable. The results are shown in column (2) of Table 3. We find that founder CEO attractiveness is positively related to $B H A R$, indicating that the CEO beauty premium may persist in the long term. Despite a substantial drop in sample size due to data availability, the association of founder CEO attractiveness with BHAR is positive, (weakly) significant $(p<.1)$, and of large economic magnitude. A 1-SD increase of founder CEO attractiveness leads to an estimated increase of BHAR equal to $21.3 \%$. These results support $\mathrm{H} 3$.

\section{2 | Post hoc analysis}

Hypothesis $\mathrm{H} 1$ predicts a positive association between founder CEO attractiveness and ICO firm valuation. Following the statistical discrimination argument (see also Arrow, 1998), in absence of more reliable indicators of firms' quality, ICO investors recognize that firms led by more attractive founder CEOs are more likely to be more productive because of their CEOs' superior managerial abilities, most notably related to their social skills. Hence, investors are more inclined to invest in firms led by these founder CEOs, and these firms will enjoy more favorable ICO valuations.

As described in Section 3.1, an alternative conceptual is stereotype-based. That is, ICO investors may assign greater valuations to firms led by more attractive founder CEOs because they have a positive stereotypical bias in favor of these individuals and (possibly mistakenly) perceive them as more trustworthy, likable, intelligent, 

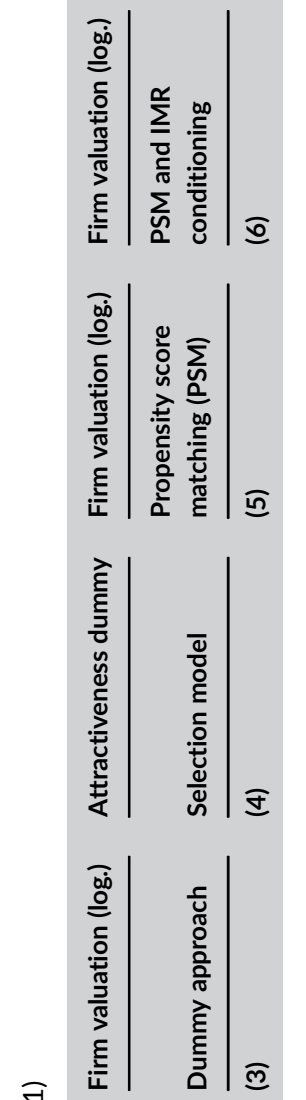

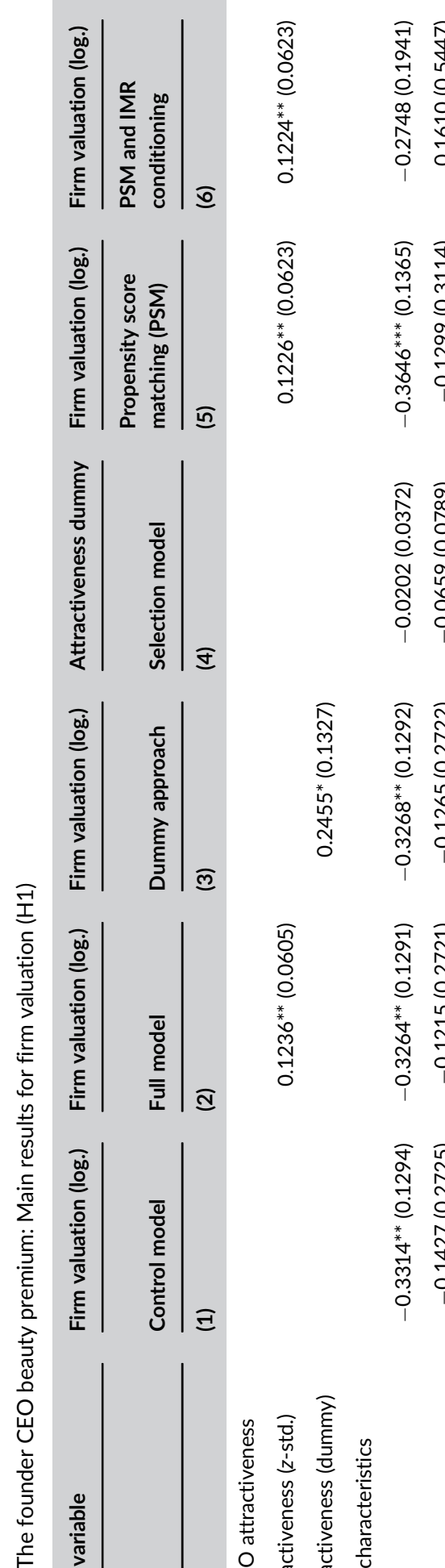

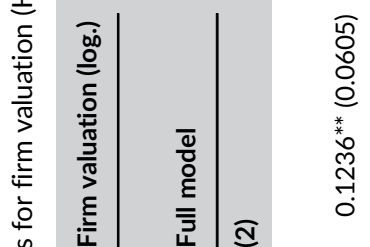

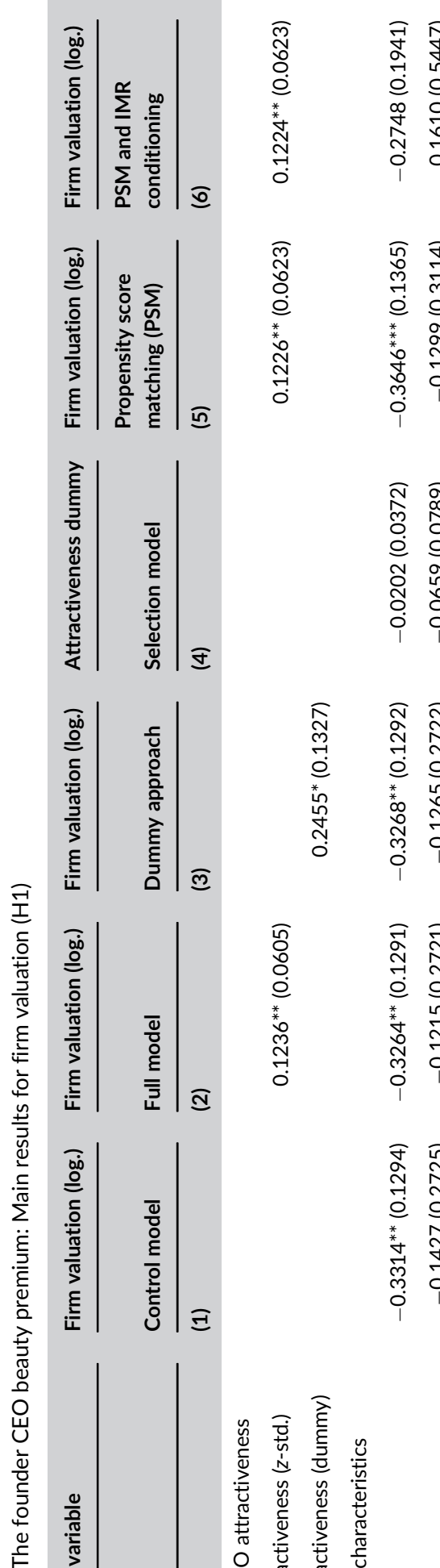

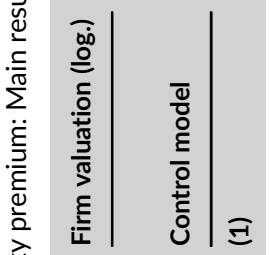

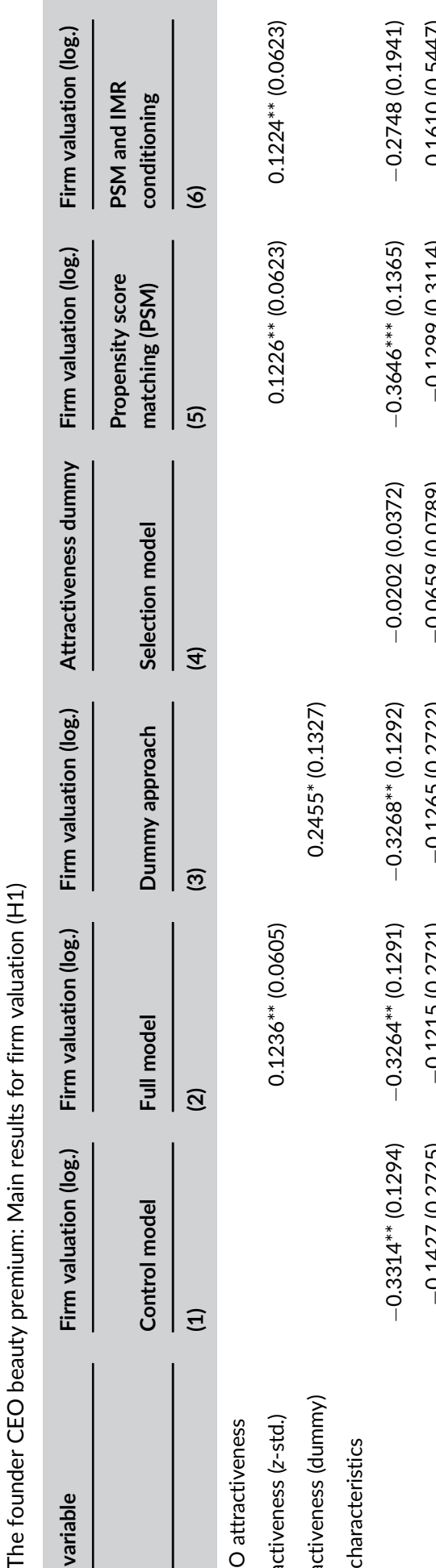

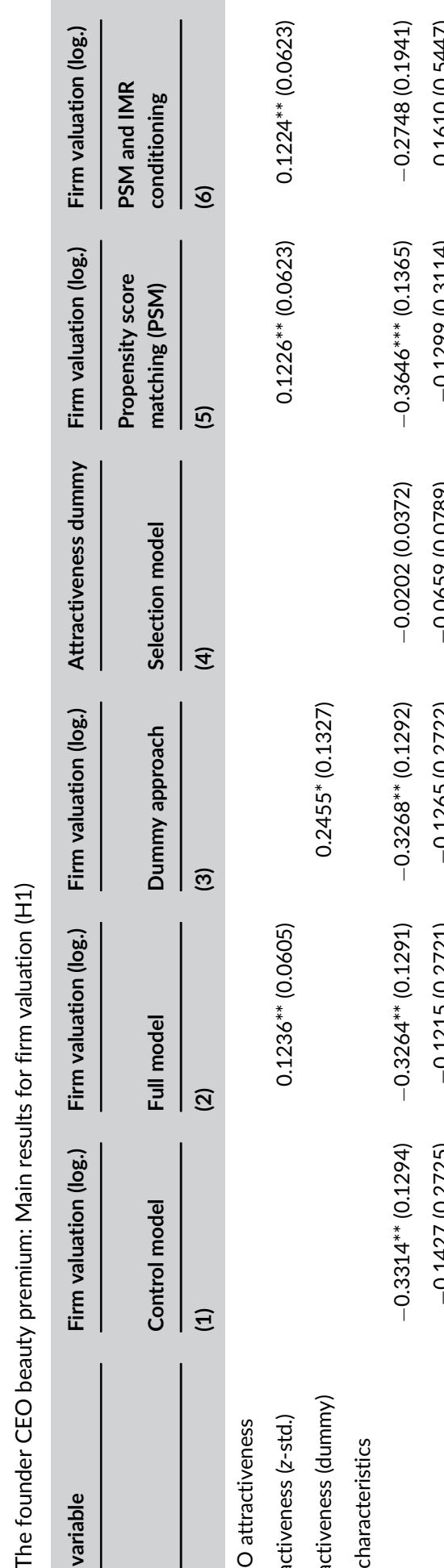

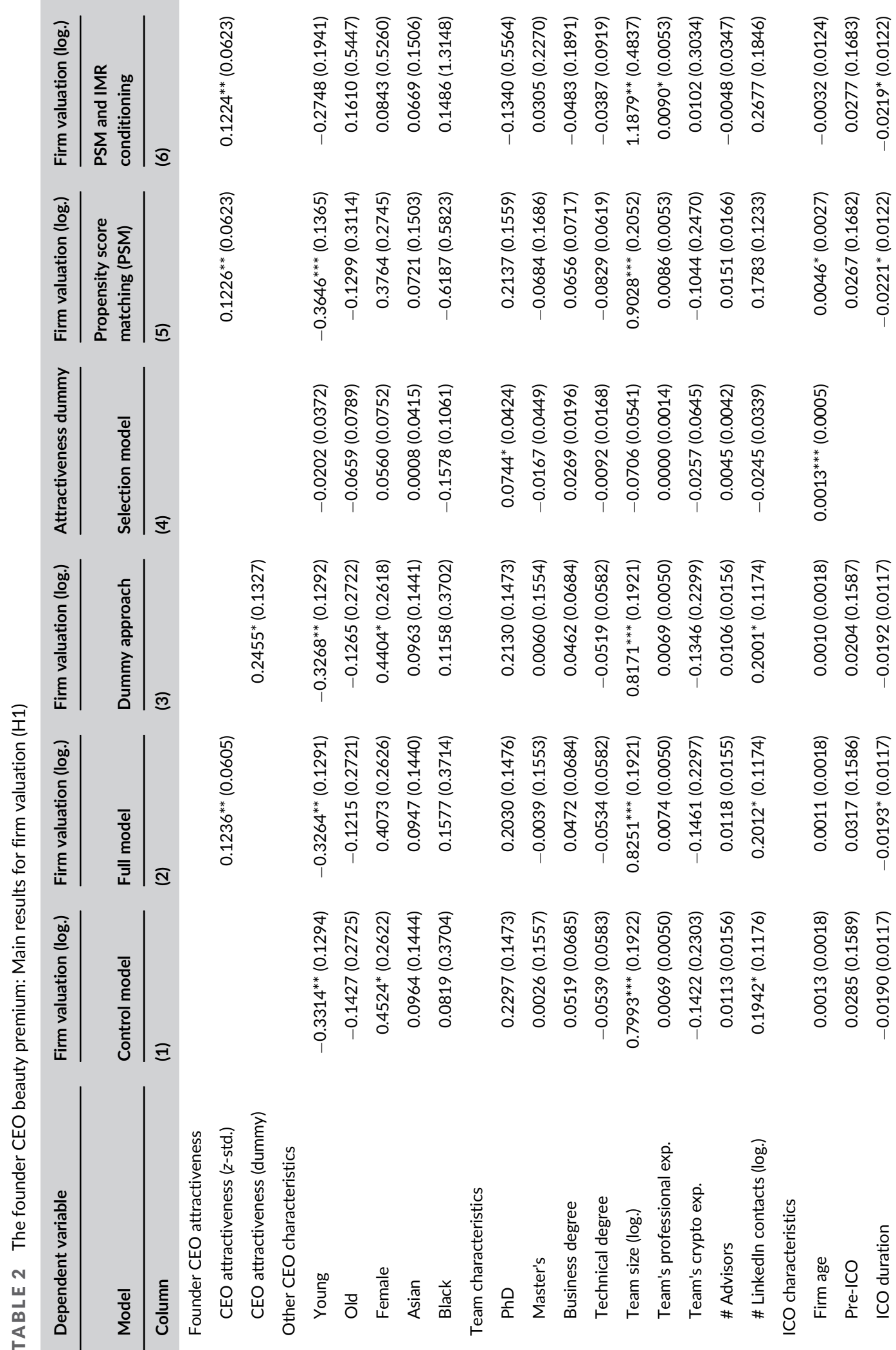

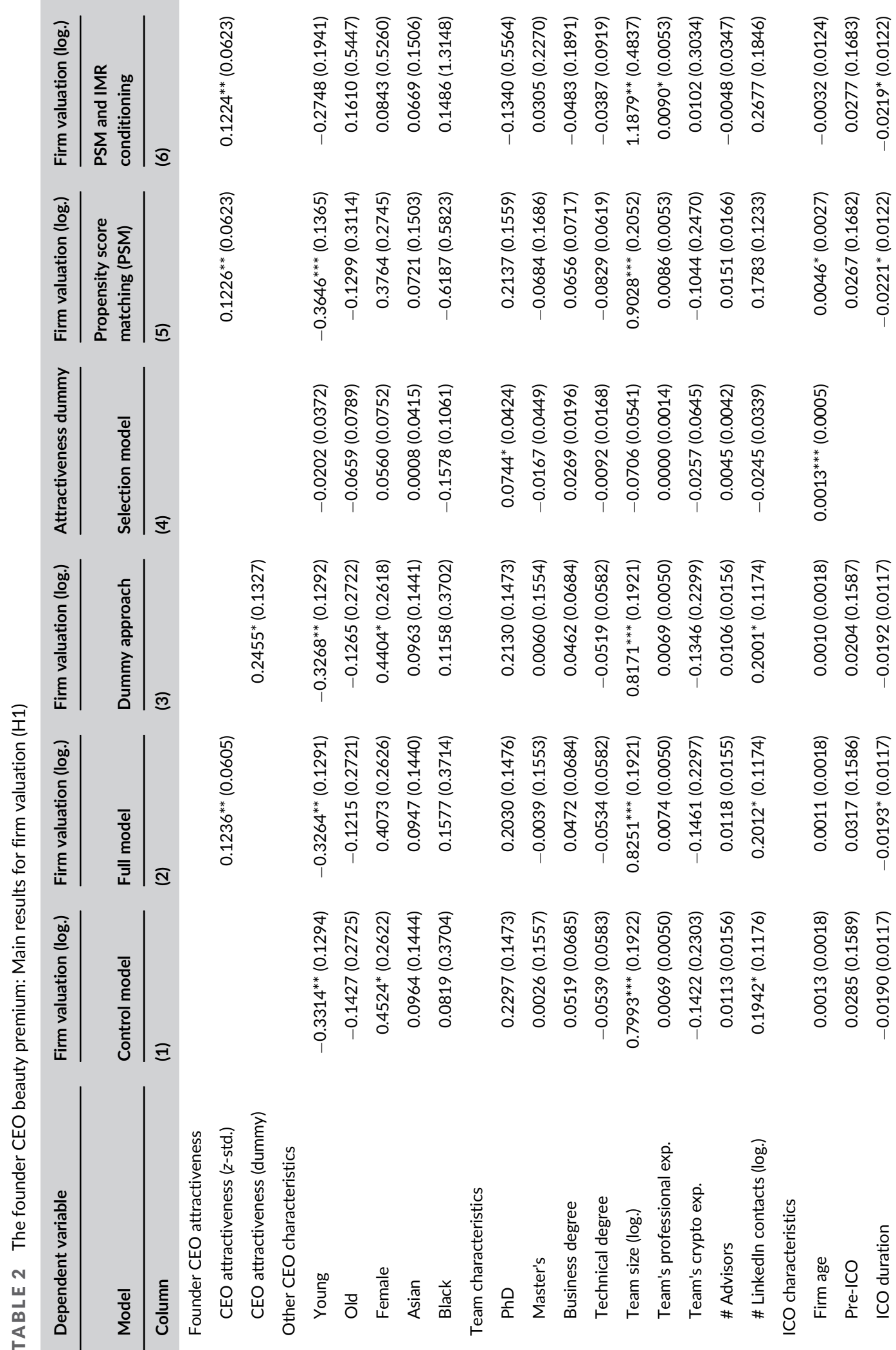

으 $\widehat{\infty}$

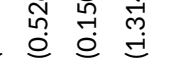

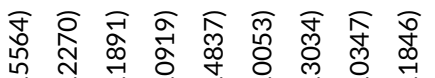

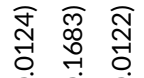

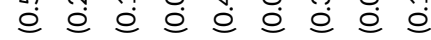

○ 0

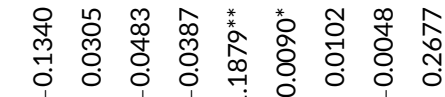

藏

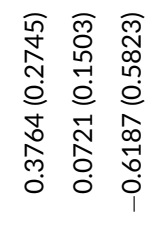

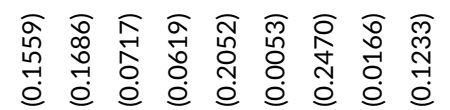

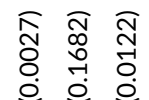

은

苻

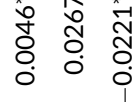

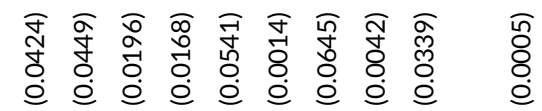

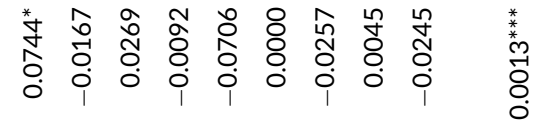

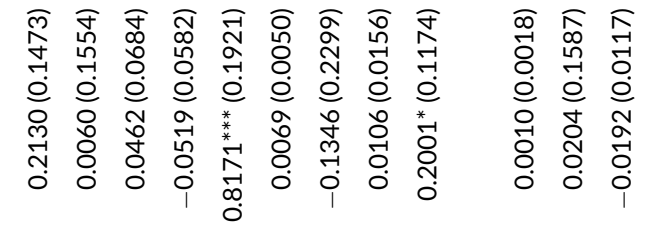




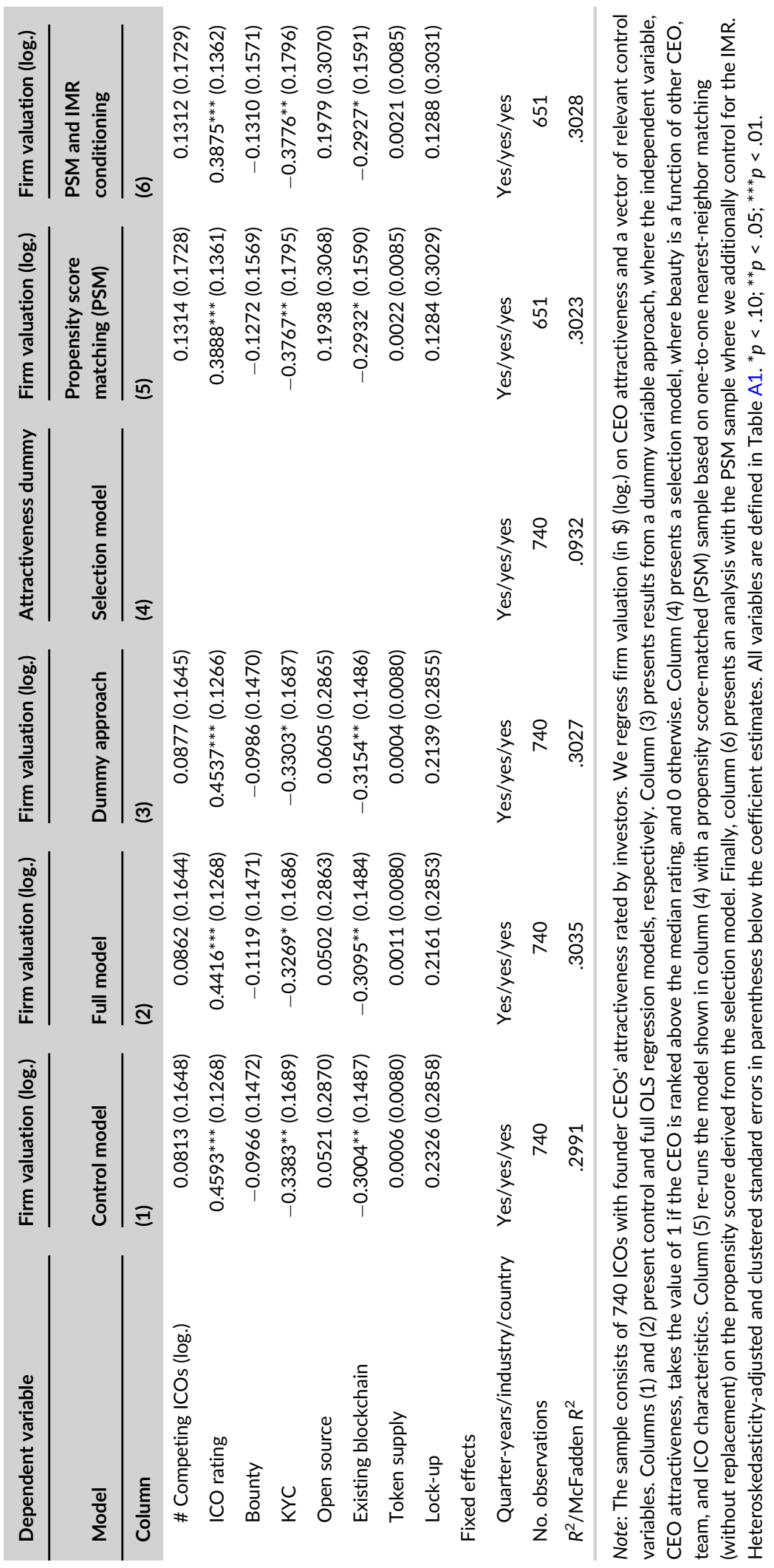


competent, and ultimately performant. For example, the tokens sold in ICOs can later be redeemed for firms' products and services but investors have little certainty that these firms will develop them in line with their promises (Fisch, 2019; Momtaz, 2020a). In case firms renege, investors have hardly any options to file legal suits, as cryptocurrency tokens do not generally fall under securities law. Thus, classic investor protection laws do not apply in most jurisdictions (Howell et al., 2020). In this case, ICO investors may show a preference for firms led by more attractive CEOs because they perceive them as more trustworthy, and rely on the founder CEOs' perceived trustworthiness to assess the probability that the firm will deliver what was promised. Other common stereotypes that could similarly explain the greater inclination of ICO investors to provide greater funding to firms led by more attractive founder CEOs include competence, likeability, and intelligence (Berggren et al., 2010; Graham et al., 2017).

To discriminate between the two theoretical mechanisms underlying the relationship between founder CEOs' attractiveness and firm valuation, we conduct a post hoc analysis in which we empirically test whether the beauty premium observed in our main analysis is mediated by stereotypical biases. If a full mediation exists, it could be concluded that the alleged productivity advantages of firms led by more attractive CEOs do not play any substantive role in influencing ICO firm valuations. Conversely, if a mediation is not evident, either because ICO investors do not perceive more attractive founder CEOs as more trustworthy, likable, intelligent, and/or competent, or because these perceived founder CEO characteristics are unrelated to firm valuation, it would therefore be deduced that the explanatory power of stereotypical biases is limited. Lastly, evidence that the relationship is partially mediated by ICO investors' stereotypical biases would suggest that both theoretical mechanisms illustrated above are possibly active.

Our mediation model follows the bootstrapping approach suggested in Preacher and Hayes (2004) and Hayes (2009). This approach allows us to overcome the common criticisms of Baron and Kenny's (1986) widely-used causal steps approach (e.g., low power, does not quantify indirect effects) (Fritz \& MacKinnon, 2007; MacKinnon, Lockwood, Hoffman, West, \& Sheets, 2002). Our mediation analysis uses bootstrapping to generate an empirical distribution of the indirect effect, which then allows us to infer more robust p-values. Specifically, we resample with replacement 5,000 times and compute the indirect effects each time. We then infer from the empirical distribution

TABLE 3 Firm-related and market-related sentiment $(\mathrm{H} 2 \mathrm{a}$ and $\mathrm{H} 2 \mathrm{~b})$ and post-ICO performance (BHAR) (H3)

\begin{tabular}{|c|c|c|}
\hline Dependent variable & Firm valuation (log.) & BHAR (6 months) (log.) \\
\hline Hypothesis & $\mathrm{H} 2 \mathrm{a}$ and $\mathrm{H} 2 \mathrm{~b}$ & H3 \\
\hline Column & (1) & (2) \\
\hline CEO attractiveness ( $z$-std.) & $0.1254^{* *}(0.0589)$ & $0.2133^{*}(0.1285)$ \\
\hline$\times$ firm-related sentiment & $-0.0020^{* *}(0.0009)$ & - \\
\hline$\times$ market-related sentiment & $-0.0036^{*}(0.0019)$ & - \\
\hline$\times$ firm-related sentiment $\times$ market-related sentiment & $0.0003^{*}(0.0002)$ & - \\
\hline Firm-related sentiment & $0.0604^{* *}(0.0276)$ & - \\
\hline Market-related sentiment & $0.1479 *(0.0764)$ & - \\
\hline Firm-related sentiment $\times$ market-related sentiment & $-0.0148^{* * *}(0.0054)$ & - \\
\hline Controls and fixed effects & Yes & Yes \\
\hline No. of observations $\left(R^{2}\right)$ & $649(.302)$ & $249(.097)$ \\
\hline
\end{tabular}

Note: Column (1) presents the results from moderation models to assess $\mathrm{H} 2$. We regress firm valuation of CEO attractiveness and interactions with firm-related and market-related sentiment, and a vector of relevant control variables. The dependent variable is firm valuation (in \$) (log.). Column (2) presents an OLS regression model with buy-and-hold arithmetic returns (BHARs) as the dependent variable (H3). Heteroskedasticity-adjusted and clustered standard errors are in parentheses below the coefficient estimates. All variables are defined in Table A1. For brevity, control variables are suppressed because they are very similar to those reported in Table $2 .{ }^{*} p<.10 ;{ }^{* *} p<.05 ;{ }^{* * *} p<.01$. 
the smallest $p$-value at which the null hypothesis (i.e., the indirect effect is statistically indifferent from zero) can be rejected.

Table 4 reports the mediation results for the stereotype-based explanations. We report the indirect, direct, and total effects for each potential stereotype-based explanation, that is, trustworthiness, competence, likability, and intelligence in columns (1), (2), (3), and (4), respectively. We find very little support for significant indirect effects. In particular, the indirect effects of trustworthiness, competence, and intelligence are statistically non-significant. Only the indirect effect of likability is somewhat significant, with a $p$-value of .084 , even though the economic significance for the total effect is relatively small. ${ }^{11}$ In contrast, the direct effects are always statistically and economically highly significant $(p<.01)$. Overall, these results suggest that ICO investors' firm valuation is a function of CEO attractiveness that is not substantially partially mediated by stereotype-based explanations.

\section{3 | Robustness checks: Additional surveys to address issues of reverse causality (Survey 2 and Survey 3)}

We administered two additional surveys to assess the robustness of the results and to mitigate endogeneity concerns. Tables 5 and 6 provide a comparative overview of the surveys conducted in this study.

In the main Survey (Survey 1), ICO investors were asked to rate the attractiveness of CEOs of firms in which the investors had invested. This approach has a high ecological validity because it uses the agents (ICO investors) whose decisions are the focus of our theoretical hypotheses. However, several issues arise because ICO investors may evaluate CEOs of firms with higher ICO valuations or higher post-ICO returns as more attractive (e.g., reverse causality, confirmation bias, or recall bias). Also, self-selection may bias the estimates if investors only selected those CEOs of whom they had a better memory, or when their selection was affected by information about the startup that surfaced only after they had invested.

We considered these issues in our study design and developed two additional surveys that vary important parameters to minimize such biases. Specifically, we conducted Survey 2, in which we asked a different set of ICO investors to evaluate the CEO attractiveness for firms they had not previously invested in. This minimizes a potential recall bias while maintaining a high degree of ecological validity. In Survey 2, each participant was given 40 randomly selected CEO photos to assess. This resulted in 5,116 photo assessments by 213 respondents. Again, only CEOs that had been rated at least three times were included in the final sample. The correlation between the original founder CEO attractiveness measurement (Survey 1 ) and Survey 2 is 0.54 , indicating the absence of bias in the econometric results. For further confirmation, all main models were re-estimated with the average CEO attractiveness score from Survey 2. The results, reported in Table 6, Column 2, indicate that our results are robust. Column 1 reports the results based on Survey 1 for comparison.

However, common latent factors among ICO investors may bias the first two surveys in that the perception of certain facial attributes may differ among ICO investors and the overall non-investor population. To further minimize such biases and to increase the reliability of our results, we conducted Survey 3, in which we asked a set of individuals without any background knowledge on ICOs to rate the attractiveness of a random sample of ICO firms' founder CEOs. The respondents were paid to assess the photos and were hired from online platforms such as www. freelancer.com and www.upwork.com. The main requirement to participate in the survey was that the freelancer was not familiar with the ICO/startup financing context. Additionally, endogeneity issues such as reverse causality might still bias the results. Berggren et al. (2010) state that more successful individuals may have access to more resources that make them appear more attractive (e.g., more expensive clothes and hair stylists, better photographers). To rule out such bias, we modified all CEO photographs used in Survey 3 in such a way that only the face (no outfit, only minimal hair) was visible. Additionally, each photograph was converted to grayscale and the light and contrast ratios were normalized to an average level. The remaining design of the survey was the same as in Survey 2 , and each respondent evaluated 40 randomly selected photos. This resulted in 5,243 assessments by 


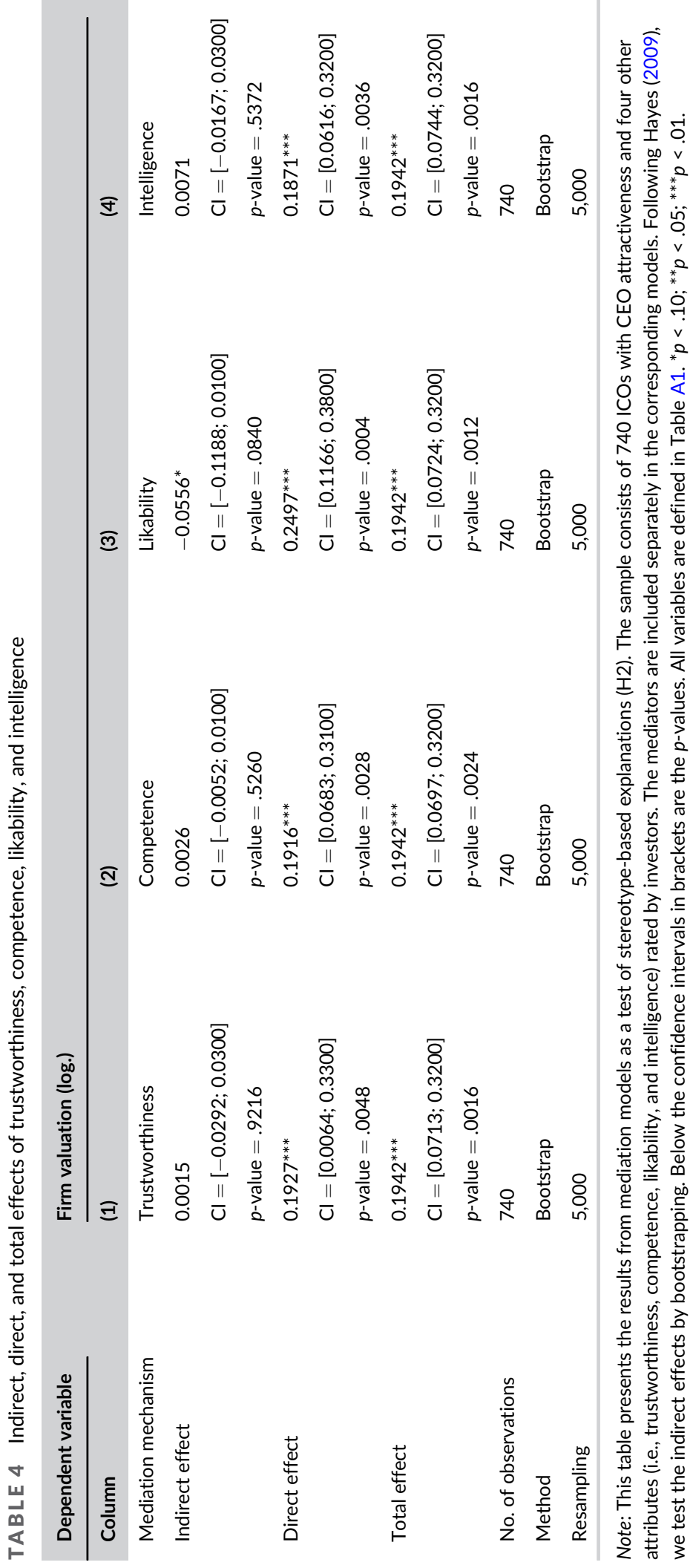


197 respondents. The correlation between the original CEO attractiveness measure and the one obtained from Survey 3 is 0.40 . Again, all models were re-estimated with this measure of CEO attractiveness. Column 3 of Table 6 shows that the estimates of the beauty premium are very similar to those in the regression models based on Survey 1. This suggests that our estimates of the founder CEOs' beauty premium are robust even when using attractiveness ratings provided by individuals unfamiliar with the ICO context.

\section{6 | DISCUSSION AND IMPLICATIONS}

In this study, we investigate the effect of founder CEO attractiveness on firm valuation in the context of ICOs. Our empirical results provide strong support for the existence of a founder CEO beauty premium: a 1-SD increase in founder CEO attractiveness is associated with a $13.2 \%$ increase in firm valuation ( $\$ 1.58 \mathrm{~m}$ for the mean ICO firm

TABLE 5 Overview of the three surveys we conducted

$\begin{array}{llllll}\text { Survey } & \text { Respondents } & \text { Context } & \text { Selection of photos } & \text { \# respondents } & \text { \# assessments } \\ \text { Survey } 1 \text { (main) } & \text { ICO investors } & \text { Known } & \begin{array}{c}\text { Self-selection } \\ (1-43 \text { per respondent })\end{array} & 633 & 4,452 \\ \text { Survey 2 } & \text { Non-investors } & \text { Known } & \begin{array}{c}\text { Random } \\ (40 \text { per respondent })\end{array} & 213 & 5,116 \\ \text { Survey 3 } & \text { Non-investors } & \text { Unknown } & \begin{array}{c}\text { Random } \\ (40 \text { per respondent })\end{array} & 197 & 5,243\end{array}$

Note: This table provides an overview of the three surveys that we conducted to measure CEO attractiveness. Survey $A$ is our main survey and was conducted among investors who had invested in the specific ICO for which they provided an attractiveness rating. Survey B was conducted among investors with ICO investment experience but who had not invested in the particular ICO they rated. Survey $\mathrm{C}$ was conducted among a random set of individuals without prior knowledge of ICOs. Also, survey $\mathrm{C}$ used manipulated photos to address endogeneity concerns (e.g., "dress for success" or "bad hair day" bias).

TABLE 6 Robustness tests based on additional surveys

\begin{tabular}{|c|c|c|c|}
\hline Survey & Survey 1 (main) & Survey 2 & Survey 3 \\
\hline Reported coefficient & $\begin{array}{l}\text { CEO attractiveness } \\
\text { (z-std.) }\end{array}$ & $\begin{array}{l}\text { CEO attractiveness } \\
\text { (z-std.) }\end{array}$ & $\begin{array}{l}\text { CEO attractiveness } \\
\text { (z-std.) }\end{array}$ \\
\hline Column & (1) & (2) & (3) \\
\hline $\begin{array}{l}\text { Table } 2 \text {, Column } 2 \\
\text { (firm valuation, main model) }\end{array}$ & $0.1236^{* *}(0.0605)$ & $0.1207^{* *}(0.0608)$ & $0.1138^{*}(0.0602)$ \\
\hline $\begin{array}{l}\text { Table } 2 \text {, Column } 3 \\
\text { (firm valuation, dummy approach) }\end{array}$ & $0.2455^{*}(0.1327)$ & $0.2561^{* *}(0.1213)$ & $0.2225^{*}(0.1217)$ \\
\hline $\begin{array}{l}\text { Table 3, Column } 1 \\
\quad \text { (moderation effects, main model) }\end{array}$ & $0.1254^{* *}(0.0589)$ & $0.1241^{*}(0.0687)$ & $0.1086^{*}(0.0640)$ \\
\hline Table 3, Column 2 (BHAR) & $0.2133^{*}(0.1285)$ & $0.2413(0.1605)$ & $0.1907 *(0.1149)$ \\
\hline
\end{tabular}

Note: This table presents re-estimated CEO attractiveness coefficients for all main models in this study, based on additional investor ratings of CEO attractiveness from the control and endogeneity surveys described in Table 5. Other controls are suppressed for brevity. The models in column (1) are shown for the sake of comparability. Column (2) reports results from input variables based on the control survey. Column (3) does the same with input variables based on the endogeneity survey. Heteroskedasticity-adjusted standard errors are in parentheses below the coefficient estimates. All variables are defined in Table A1. ${ }^{*} p<.10 ;{ }^{* *} p<.05 ;{ }^{* * *} p<.01$. 
with a valuation of $\$ 11.99 \mathrm{~m}$ ). Founder CEO attractiveness, therefore, constitutes an important determinant of ICO success. We do not find evidence that the effect of founder CEO attractiveness is substantially mediated by investors' stereotype-based evaluations related to perceived trustworthiness, likeability, intelligence, or competence. However, firm-related and market-related sentiments negatively influence the CEO attractiveness-firm valuation relation. This suggests that CEO attractiveness indeed serves as a reference point for investors, but only when investment-related information is scarce. We also find that firms led by more attractive CEOs enjoy superior postICO performance as reflected in the returns of a buy-and-hold investment strategy. Our results are robust to the use of different econometric techniques and different survey-based measures of CEO attractiveness.

Our findings contribute to entrepreneurship research by focusing attention on the founder CEO's "beauty premium." While the beauty premium has been documented in fields as diverse as the labor market (Hamermesh \& Biddle, 1994), education (Cipriani \& Zago, 2011), politics (Berggren et al., 2010), charitable giving (Jenq et al., 2015; Park et al., 2019), finance (Blankespoor et al., 2017; Cao et al., 2020; Price, 2008; Ravina, 2019), and strategy (Cook \& Mobbs, 2019; Halford \& Hsu, 2020), the effect of founder CEO attractiveness on entrepreneurial outcomes remains relatively underresearched. A few previous studies argue in favor of the existence of an entrepreneurial beauty premium. Self-employed individuals are judged more attractive than salaried employees, have greater income when they are more attractive, and their ideas for new products are rated more favorably (Baron et al., 2006; Patel \& Wolfe, 2019). However, whether ventures established by more attractive entrepreneurs are more successful than other ventures is still unclear. In particular, we do not know whether more attractive entrepreneurs manage to obtain greater external resources, and above all why.

Our study documents the existence of a sizable founder CEO beauty premium in firms' ICO valuation. It also provides new insights into the origin of this beauty premium. Indeed, our results suggest that, in accordance with the statistical discrimination argument, founder CEO attractiveness is an (admittedly noisy) indicator of firm quality in contexts such as ICOs, where typically there is extremely high uncertainty and investors lack reliable information on firms' quality and prospects. Accordingly, we find that when more information is available to ICO investors (e.g., because market-related and/or firm-related sentiments are positive), founder CEO attractiveness becomes less salient for ICO investors' decisions. The evidence that firms led by more attractive founder CEOs outperform other firms in the post-ICO period also indicates that in the absence of more reliable indicators of firm performance, ICO investors are probably right in using founder CEO attractiveness as a predictor of firm success. Conversely, our results are not consistent with the argument that the beauty premium enjoyed by firms led by more attractive founder CEOs can simply be traced to the stereotypical biases which may shape the decisions of economic agents (in our case, ICO investors), and is inconsequential for firm performance.

We also contribute to research in entrepreneurial finance. Previous work documents the importance of the CEO for early-stage ventures (see, e.g., Kaplan, Sensoy, \& Strömberg, 2009). This research has frequently identified the educational achievements and professional experience of firms' founder CEOs (and other top management team members) as one of the most important or as the most important criterion guiding investors' funding decisions (Bernstein, Korteweg, \& Laws, 2017; Gompers, Gornall, Kaplan, \& Strebulaev, 2020). A more recent stream of literature highlights the importance of the appearance of entrepreneurs in pitches, such as their use of figurative language (Clarke, Cornelissen, \& Healey, 2019; Tsay, 2020) or their facial expression of emotions (Momtaz, 2021a, 2021d; Stroe, Sirén, Shepherd, \& Wincent, 2020; Warnick, Davis, Thomas, Allison, \& Anglin, 2021), to attract investors. These studies suggest that in a context characterized by extreme uncertainty about firms' quality and prospects and great information asymmetries between entrepreneurs and investors, investors' decisions are based on simple but effective heuristics (their "gut feel," Huang \& Pearce, 2015). Although a few previous studies (Brooks et al., 2014; Davila \& Guasch, 2020) show that more attractive entrepreneurs are more likely to obtain external finance from investors than their less attractive peers, the theoretical mechanisms underlying this positive association have not been thoroughly investigated. Our study takes an important step forward in this direction by documenting that investors value firms led by more attractive founder CEOs higher when the information set on which they base their investment decisions is limited, and in doing so, they obtain higher returns. 
Lastly, our study contributes to the growing literature on factors explaining success in ICO financing (e.g., Fisch, 2019; Howell et al., 2020). While this research documents the important role that founder CEOs play in ICO success and post-ICO performance, we show that founder CEO attractiveness is a critical and previously overlooked condition that shapes ICO outcomes. We highlight the existence of a sizable founder CEO beauty premium in ICOs, and in so doing we extend recent ICO research that has considered the association between founder CEOs' appearance and firm ICO valuation (Huang et al., 2021; Momtaz, 2021a).

Our study has limitations that open avenues for further research. First, one may wonder about the external validity of our findings. ICOs are an appropriate setting to test the existence of the founder CEO beauty premium when the amount of information available is scarce because images of firms' CEOs are immediately visible to all prospective ICO investors. However, it is unclear whether our findings can be extended to other more established domains even within entrepreneurial finance, such as venture capital deals or IPOs. While founder CEO characteristics also play an important role in these more established funding settings (e.g., Gompers et al., 2020), the availability of more reliable information in those settings likely reduces the founder CEO beauty premium. Hence, our estimates may constitute an upper bound of the relationship between founder CEO attractiveness and firm valuation. The underlying theoretical mechanisms may also differ in those settings. While we assume a potential founder CEO beauty premium to be less pronounced in such established funding settings in general, some variation likely exists. For example, prior VC research highlights that the portfolio ventures' team is a critical decision criterion for VC investors when screening ventures (e.g., Block, Fisch, Vismara, \& Andres, 2019; Gompers et al., 2020). In the absence of more reliable information, a beauty premium could exist and influence investment decisions in the early stage of the VC investment process. However, only a small fraction of the ventures that are screened pass the following due diligence and negotiation stages, in which more reliable information is sought and thoroughly analyzed. Hence, the importance of a beauty premium should decline when the portfolio venture progresses along the $\mathrm{VC}$ investment process.

Conversely, a founder CEO beauty premium might exist funding setting in which less information is available. Future research could thus assess under what conditions a founder CEO beauty premium exists in other entrepreneurial finance domains. Attractiveness might indeed matter differently in digital finance than in traditional entrepreneurial finance markets or in equity rather than in debt markets. There might indeed be a gradation in the impact of beauty by stage of the VC process (e.g., screening, due diligence, negotiation, post-investment). The heterogeneity of digital finance platforms could also matter considering their role in reducing information asymmetries (Allen, Gu, \& Jagtiani, 2021). For instance, in equity crowdfunding, crowd investors have both limited screening abilities and limited information on firms that are launching a crowdfunding campaign, like in ICOs, and therefore may (correctly) use founder CEO attractiveness as an indicator of firms' quality. The beauty premium might exist in crowdfunding, but could it differ by some factors, such as age or gender, which are relevant for the inclusive potential of these markets (Cumming, Meoli, \& Vismara, 2021). Another example is the context of peer-to-peer lending (P2P), where prior research shows that soft information about borrowers, like beauty, can affect lenders' credit decisions (e.g., Ravina, 2019). A founder CEO beauty premium might also exist in angel investments since these types of very early-stage investors frequently make decisions based on their "gut feel" instead of solely relying on objective data (Huang \& Pearce, 2015). Relatedly, one could also take a step further and investigate the existence of a founder CEO beauty premium (and its drivers) in other settings involving, for example, customers or employees, rather than investors.

Another limitation refers to the data considered in our analyses. For example, we study the aggregate funding amount a venture raises with its ICO. Ideally, one would consider the amount invested by each investor, to explore whether the size of the founder CEO beauty premium varies with investors' characteristics (e.g., small and large individual investors, more or less experienced investors venture capital funds, hedge funds, corporations). However, such information is not available as of yet, mostly due to the high degree of anonymity in ICOs. Also, our attractiveness measure (as well as the measures of our mediators in the post hoc analysis) are based on a single item and thus relatively crude. Even though this approach is in line with prior research (e.g., Berggren et al., 2010; Blankespoor et al., 2017; Graham et al., 2017; Jenq et al., 2015), a more nuanced approach to capturing attractiveness and other characteristics of founder CEOs might enable further insights. In sum, future research should extend our findings by 
utilizing richer data to more carefully assess how founder CEO attractiveness influences firm valuation and performance. This includes the further exploration of other moderators that potentially shape the CEO attractiveness-firm valuation relationship.

Third, previous studies in labor economics find that attractive candidates are more often contacted for job interviews. This evidence holds only (Ruffle \& Shtudiner, 2015) or especially (López Bóo et al., 2013) if they are male. Ruffle and Shtudiner (2015) explore several explanations for this discrimination against attractive women, including female jealousy and envy. In the entrepreneurship domain, the very few previous studies that investigate the beauty premium of male and female entrepreneurs tend to support the view that attractiveness matters more for male entrepreneurs (e.g., Brooks et al., 2014; Patel \& Wolfe, 2019; see Baron et al., 2001 for a divergent view). The domain of digital finance in general, and our sample specifically, are dominated by male founder CEOs. While we do control for the founder CEO's gender and do not find differences between the attractiveness ratings, it is unclear how our results can be extended to other funding settings that might be less male-dominated. For example, Park et al. (2019) show that in charitable crowdfunding, female recipients enjoy a more pronounced beauty premium than male recipients, especially among male donors. It would be interesting to assess whether the relationship between founder CEO attractiveness and firm performance is gender-specific, and why.

Relatedly, culture might intersect with the importance of beauty. A large literature has documented the importance of culture that could shape the decision-making processes of individuals, including investors in public offerings (Cumming, Meles, Sampagnaro, \& Verdoliva, 2019). Even if scholars agree that the perception of beauty is stable across cultures (Maestripieri et al., 2017), investors' reaction to the attractiveness of founder CEOs' may not. Unfortunately, a substantial fraction of the ICOs ventures in our sample resides in locations such as the British Virgin Islands or the Cayman Islands, for which cultural variables (e.g., Hofstede's cultural constructs) are not available. Future research might overcome these limitations.

\section{7 | CONCLUSIONS}

Our empirical results associate increased founder CEO attractiveness with higher ICO valuations and post-ICO performance. These findings have important implications for investors and entrepreneurs. A straightforward implication of our findings for investors is to invest in the ICOs of firms led by more attractive founder CEOs since they tend to achieve higher valuations and higher returns in the aftermarket. This information is particularly useful in an investment context that is characterized by a paucity of information, and for investors who do not have the capabilities or resources to perform extensive due diligence processes. After all, assessing attractiveness is straightforward. Our findings are also interesting for startups seeking external finance in a context characterized by extreme uncertainty and strong information asymmetry such as ICOs. If startups can appoint attractive leaders, they may have better access to growth capital.

\section{DATA AVAILABILITY STATEMENT}

Data sharing is not applicable to this article as no new data were created or analyzed in this study.

\section{ORCID}

Christian Fisch (10) https://orcid.org/0000-0003-3609-7193

\section{ENDNOTES}

${ }^{1}$ Another explanation, inspired by Becker's (1957) "taste for discrimination" model, argues that managers have innate personal preferences for attractive individuals. Thus, they have intrinsic incentives to positively discriminate for attractive candidates in hiring and promotion decisions, without any substantive positive effect on economic output.

2 The "beauty is beastly" perspective in social psychology points out that in certain situations, individuals' attractiveness may have harmful consequences, as it can motivate individuals to engage in social comparisons leading to negative 
perceptions of the target of the comparison (e.g., Agthe, Spörrle, \& Maner, 2011). However, attractive founder CEOs of ICO firms are unlikely to be harmed by "beauty is beastly" social comparisons on the part of ICO investors. In fact, these social comparisons generally are unlikely to produce negative effects when the target of the comparison, as in this case, is not an in-group member (see Patel \& Wolfe, 2019, p. 5 for a similar argument). However, in our robustness checks, we investigate an inverse $U$-shaped relation between founder CEOs' attractiveness and their firms' ICO valuation.

${ }^{3}$ Our main results are similar in magnitude and significance if these observations are excluded from the sample.

${ }^{4}$ We were very strict and only sampled from ICOs for which information to construct the independent variable was available. However, to ensure a large number of observation, we employed King, Honaker, Joseph, and Scheve's (2001) multiple imputation method for a few missing values among the control variables.

5 The total response rate for our main survey is approximately equal to $17 \%$.

${ }^{6}$ We also checked interrater reliability and confirmed that Cronbach's alpha exceeds the commonly agreed-upon threshold of 0.7 (Halford \& Hsu, 2020; Momtaz, 2021a).

7 In a post hoc analysis, we run regressions using the most common stereotypes considered in prior attractiveness research (e.g., Berggren et al., 2010; Graham et al., 2017) as mediators. Therefore, the survey also asked respondents to rate each CEO's trustworthiness, competence, likeability, and intelligence. Each variable is scaled from 1 (e.g., not trustworthy at all) to 10 (e.g., very trustworthy). These measures are also z-standardized As is usual in studies based on surveys in which respondents are asked to judge pictures of individuals along several dimensions, all these measures are based on one single item and are averaged across independent raters (see, e.g., Jenq et al., 2015; Blankespoor et al., 2017; Graham et al., 2017 for a similar approach).

8 Technical degrees include degrees in engineering and computer sciences. Business degrees include degrees in management, economics, and finance. Additional analyses show that our results are robust in expressing the team characteristics variables as the number of team members with such degrees or as the fraction of team members with such degrees relative to the team size. These additional analyses are available from the authors upon request.

9 This approach leads to the best-matching result based on two frequently used evaluation criteria. First, we check for statistical significance of the differences in means in the two groups (CEO attractiveness dummy $=1$ vs. 0 ) before and after the matching, and find a reassuring decrease in most $p$-values after the matching. Second, McFadden's $R^{2}$ increases when we estimate the prediction model with the post-matching sample.

10 The coefficient of the interaction term between firm-related and market-related sentiment is negative. This indicates that firm-related and market-related sentiment are informational substitutes. When firm-related sentiment is more positive, market-related sentiment is less important for investors, and vice versa.

${ }^{11}$ As is apparent from Table 1, founder CEO attractiveness is positively and significantly correlated with trustworthiness (0.26; $p<.01)$, likeability $(0.46 ; p<.01)$, and intelligence $(0.17 ; p<.01)$, but is not correlated with competence $(0.06 ; p>.1)$.

\section{REFERENCES}

Agthe, M., Spörrle, M., \& Maner, J. K. (2011). Does being attractive always help? Positive and negative effects of attractiveness on social decision making. Personality and Social Psychology Bulletin, 37(8), 1042-1054.

Allen, F., Gu, X., \& Jagtiani, J. (2021). A survey of fintech research and policy discussion. Review of Corporate Finance, 1, 259-339.

An, J., Duan, T., Hou, W., \& Xu, X. (2019). Initial coin offerings and entrepreneurial finance: The role of founders' characteristics. The Journal of Alternative Investments, 21(4), 26-40.

Arrow, K. J. (1973). The theory of discrimination. In O. Ashenfelter \& A. Rees (Eds.), Discrimination in labor markets. Princeton, NJ: Princeton University Press.

Arrow, K. J. (1998). What has economics to say about racial discrimination? Journal of Economic Perspectives, 12(2), 91-100.

Baron, R. A., Markman, G. D., \& Bollinger, M. (2006). Exporting social psychology: Effects of attractiveness on perceptions of entrepreneurs, their ideas for new products, and their financial success. Journal of Applied Social Psychology, 36(2), 467-492.

Baron, R. A., Markman, G. D., Hirsa, A., Baron, R. A., Markman, G. D., \& Hirsa, A. (2001). Perceptions of women and men as entrepreneurs: Evidence for differential effects of attributional augmenting. Journal of Applied Psychology, 86(5), 923-929.

Baron, R. M., \& Kenny, D. A. (1986). The moderator-mediator variable distinction in social psychological research: Conceptual, strategic, and statistical considerations. Journal of Personality and Social Psychology, 51(6), 1173-1182.

Barrick, M. R., Shaffer, J. A., \& DeGrassi, S. W. (2009). What you see may not be what you get: Relationships among selfpresentation tactics and ratings of interview and job performance. Journal of Applied Psychology, 94(6), 1394-1411.

Becker, G. (1957). The economics of discrimination. Chicago, IL: University of Chicago Press. 
Bellavitis, C., Cumming, D., \& Vanacker, T. (2020). Ban, boom, and echo! Entrepreneurship and initial coin offerings. Entrepreneurship Theory and Practice, 1-34. https://doi.org/10.1177/1042258720940114

Bellavitis, C., Fisch, C., \& Wiklund, J. (2021). A comprehensive review of the global development of initial coin offerings (ICOs). Journal of Business Venturing Insights, 15, e00213.

Benedetti, H., \& Kostovetsky, L. (2021). Digital tulips? Returns to investors in initial coin offerings. Journal of Corporate Finance, 66, 101786.

Berggren, N., Jordahl, H., \& Poutvaara, P. (2010). The looks of a winner: Beauty and electoral success. Journal of Public Economics, 94, 8-15.

Bernstein, S., Korteweg, A., \& Laws, K. (2017). Attracting early stage investors: Evidence from a randomized field experiment. The Journal of Finance, 72(2), 509-538.

Biddle, J. E., \& Hamermesh, D. S. (1998). Beauty, productivity, and discrimination: lawyers' looks and lucre. Journal of Labor Economics, 16(1), 172-201.

Blankespoor, E., Hendricks, B. E., \& Miller, G. S. (2017). Perceptions and price: Evidence from CEO presentations at IPO roadshows. Journal of Accounting Research, 55(2), 275-327.

Block, J., Fisch, C., Vismara, S., \& Andres, R. (2019). Private equity investment criteria: An experimental conjoint analysis of venture capital, business angels, and family offices. Journal of Corporate Finance, 58, 329-352.

Boreiko, D., \& Risteski, D. (2021). Serial and large investors in initial coin offerings. Small Business Economics, 57, 10531071.

Brooks, A. W., Huang, L., Kearney, S. W., \& Murray, F. E. (2014). Investors prefer entrepreneurial ventures pitched by attractive men. Proceedings of the National Academy of Sciences, 111(12), 4427-4431.

Campino, J., Brochado, A., \& Rosa, Á. (2021). Initial coin offerings (ICOs): The importance of human capital. Journal of Business Economics, 91, 1225-1262. https://doi.org/10.1007/s11573-021-01037-w

Cao, Y., Guan, F., Li, Z., \& Yang, Y. G. (2020). Analysts' beauty and performance. Management Science, 66(9), $4315-4335$.

Chaim, P., \& Laurini, M. P. (2018). Volatility and return jumps in bitcoin. Economics Letters, 173(12), 158-163.

Chatterji, A., Delecourt, S., Hasan, S., \& Koning, R. (2019). When does advice impact startup performance? Strategic Management Journal, 40(3), 331-356.

Chen, Y., Pereira, I., \& Patel, P. C. (2021). Decentralized governance of digital platforms. Journal of Management, 47(5), 1305-1337.

Cook, D. O., \& Mobbs, S. (2019). CEO selection and executive appearance. Available at SSRN 2379577.

Cipriani, G. P., \& Zago, A. (2011). Productivity or discrimination? Beauty and the exams. Oxford Bulletin of Economics and Statistics, 73(3), 428-447.

Clarke, J. S., Cornelissen, J. P., \& Healey, M. P. (2019). Actions speak louder than words: How figurative language and gesturing in entrepreneurial pitches influences investment judgments. Academy of Management Journal, 62(2), 335-360.

Cole, R., Johan, S., \& Schweizer, D. (2021). Corporate failures: Declines, collapses, and scandals. Journal of Corporate Finance, 67, 101872.

Colombo, M. G., \& Grilli, L. (2005). Founders' human capital and the growth of new technology-based firms: A competencebased view. Research Policy, 34(6), 795-816.

Connelly, B. L., Lee, K., Hersel, M., \& Walker, J. (2020). Attractive CEOs: Let off the hook or held to a higher standard? Working Paper.

Corbet, S., \& Cumming, D. J. (2020). The wild west of ICOs. In S. Corbet, A. Urquhart, \& L. Yarovaya (Eds.), Cryptocurrency and Blockchain technology. Berlin/Boston: De Gruyter.

Cumming, D. J., Hornuf, L., Karami, M., Schweizer, D. (2020). Disentangling crowdfunding from fraudfunding. Working Paper, Max Planck Institute for Innovation \& Competition Research Paper 16-09. Retrieved from https://papers.ssrn. com/sol3/papers.cfm?abstract_id=2828919

Cumming, D. J., Meles, A., Sampagnaro, G., \& Verdoliva, V. (2019). Corporate culture and IPOs. SSRN Working Paper 3134577.

Cumming, D. J., Meoli, M., \& Vismara, S. (2021). Does equity crowdfunding democratize entrepreneurial finance? Small Business Economics, 56, 533-552.

Davila, A., \& Guasch, M. (2020). The effects of investors' perceptions and entrepreneurs' physical on firm forecasts, valuation, investments, and survival. SSRN Working Paper. https://doi.org/10.2139/ssrn.3593478.

Dion, K., Berscheid, E., \& Walster, E. (1972). What is beautiful is good. Journal of Personality and Social Psychology, 24(3), 285-290.

Drobetz, W., Momtaz, P. P., \& Schröder, H. (2019). Investor sentiment and initial coin offerings. The Journal of Alternative Investments, 21(4), 41-55.

Duarte, J., Siegel, S., \& Young, L. (2012). Trust and credit: The role of appearance in peer-to-peer lending. Review of Financial Studies, 25(8), 2455-2484.

Eagly, A. H., Ashmore, R. D., Makhijani, M. G., \& Longo, L. C. (1991). What is beautiful is good, but ...: A meta-analytic review of research on the physical attractiveness stereotype. Psychological Bulletin, 110, 109-128.

Fahlenbrach, R., \& Frattaroli, M. (2021). ICO investors. Financial Markets and Portfolio Management, 35, 1-59. 
Feingold, A. (1992). Good-looking people are not what we think. Psychological Bulletin, 111(2), 304-341.

Fisch, C. (2019). Initial coin offerings (ICOs) to finance new ventures. Journal of Business Venturing, 34(1), 1-22.

Fisch, C., Masiak, C., Vismara, S., \& Block, J. (2021). Motives and profiles of ICO investors. Journal of Business Research, 125(3), 564-576.

Fisch, C., \& Momtaz, P. P. (2020). Institutional investors and post-ICO performance: An empirical analysis of investor returns in initial coin offerings (ICOs). Journal of Corporate Finance, 64, 101679.

Fritz, M. S., \& MacKinnon, D. P. (2007). Required sample size to detect the mediated effect. Psychological Science, 18, 233-239.

Gan, J., Tsoukalas, G., \& Netessine, S. (2021). Initial coin offerings, speculation, and asset tokenization. Management Science, 67(2), 914-931.

Gompers, P. A., Gornall, W., Kaplan, S. N., \& Strebulaev, I. A. (2020). How do venture capitalists make decisions? Journal of Financial Economics, 135(1), 169-190.

Graham, J. R., Harvey, C. R., \& Puri, M. (2017). A corporate beauty contest. Management Science, 63(9), 3044-3056.

Halford, J. T., \& Hsu, H. C. (2020). Beauty is wealth: CEO appearance and shareholder value. Financial Review, 55(4), 529-556.

Hamermesh, D. S. (2011). Beauty pays: Why attractive people are more successful. Princeton, NJ: Princeton University Press.

Hamermesh, D. S., \& Biddle, J. E. (1994). Beauty and the labor market. American Economic Review, 84(5), 1174-1194.

Hayes, A. F. (2009). Beyond Baron and Kenny: Statistical mediation analysis in the new millennium. Communication Monographs, 76(4), 408-420.

Howard, M. D., Kolb, J., \& Sy, V. A. (2021). Entrepreneurial identity and strategic disclosure: Founder CEOs and new venture media strategy. Strategic Entrepreneurship Journal, 15, 3-27.

Howell, S. T., Niessner, M., \& Yermack, D. (2020). Initial coin offerings: Financing growth with cryptocurrency token sales. Review of Financial Studies, 33(9), 3925-3974.

Huang, L., \& Pearce, J. L. (2015). Managing the unknowable: The effectiveness of early-stage investor gut feel in entrepreneurial investment decision. Administrative Science Quarterly, 60(4), 634-670.

Huang, W., Vismara, S., \& Wei, X. (2021). Confidence and capital raising. Journal of Corporate Finance, 101900. https://doi. org/10.1016/j.jcorpfin.2021.101900

Jenq, C., Pan, J., \& Theseira, W. (2015). Beauty, weight, and skin color in charitable giving. Journal of Economic Behaviour and Organization, 119, 234-253.

Kaplan, S. N., Sensoy, B. A., \& Strömberg, P. (2009). Should investors bet on the jockey or the horse? Evidence from the evolution of firms from early business plans to public companies. Journal of Finance, 64(1), 75-115.

Kastelein, R. (2017). What initial coin offerings are, and why VC firms care. Retrieved from https://hbr.org/2017/03/whatinitial-coin-offerings-are-and-why-vcfirms-care

King, G., Honaker, J., Joseph, A., \& Scheve, K. (2001). Analyzing incomplete political science data: An alternative algorithm for multiple imputation. American Political Science Review, 95(1), 49-69.

Kolbe, M., Mansouri, S., \& Momtaz, P. P. (2021). Why do video pitches matter in crowdfunding? SSRN Working Paper, 3939751.

Kulchina, E. (2017). Do foreign entrepreneurs benefit their firms as managers? Strategic Management Journal, 38(8), 15881607.

Kumar, M. S., Nagarajan, N. J., \& Schlingemann, F. P. (2020). The performance of acquisitions of founder CEO firms: The effect of founder firm premium. Strategic Entrepreneurship Journal, 15, 619-646. https://doi.org/10.1002/sej.1371

Langlois, J. H., Kalakanis, L., Rubenstein, A. J., Larson, A., Hallam, M., \& Smoot, M. (2000). Maxims or myths of beauty? A meta-analytic and theoretical review. Psychological Bulletin, 126(3), 390-423.

Leitterstorf, M. P., \& Rau, S. B. (2014). Socioemotional wealth and IPO underpricing of family firms. Strategic Management Journal, 35(5), 751-760.

López Bóo, F., Rossi, M. A., \& Urzua, S. (2013). The labor market return to an attractive face: Evidence from a field experiment. Economic Letters, 118(1), 170-172.

Loughran, T., \& Ritter, J. (1995). The new issues puzzle. The Journal of Finance, 50(1), 23-51.

Lyandres, E., Palazzo, B., \& Rabetti, D. (2019). Do tokens behave like securities? An anatomy of initial coin offerings. Working Paper.

MacKinnon, D. P., Lockwood, C. M., Hoffman, J. M., West, S. G., \& Sheets, V. (2002). A comparison of methods to test mediation and other intervening variable effects. Psychological Methods, 7, 83-104.

Maestripieri, D., Henry, A., \& Nickels, N. (2017). Explaining financial and prosocial biases in favor of attractive people: Interdisciplinary perspectives from economics, social psychology, and evolutionary psychology. Behavioral and Brain Sciences, 40(19), 1-76.

Mansouri, S., \& Momtaz, P. P. (2021). Financing sustainable entrepreneurship: ESG measurement, valuation, and performance in token offerings. SSRN Working Paper, 3844259. 
Mobius, M. M., \& Rosenblat, T. S. (2006). Why beauty matters. American Economic Review, 96(1), 222-235.

Momtaz, P. P. (2020a). Initial coin offerings. PLoS One, 15(5), e0233018.

Momtaz, P. P. (2020b). Entrepreneurial finance and moral hazard: Evidence from token offerings. Journal of Business Venturing, 36, 1-24. https://doi.org/10.1016/j.jbusvent.2020.106001

Momtaz, P. P. (2020c). Initial coin offerings, asymmetric information, and loyal CEOs. Small Business Economics, 57, 975997. https://doi.org/10.1007/s11187-020-00335-x

Momtaz, P. P. (2021a). CEO emotions and firm valuation in initial coin offerings: An artificial intelligence approach. Strategic Management Journal, 42(3), 558-578.

Momtaz, P. P. (2021b). The pricing and performance of Cryptocurrency. The European Journal of Finance, 27(4-5), 367-380.

Momtaz, P. P. (2021c). The economics of crypto funds. SSRN Working Paper, 3865240.

Momtaz, P. P. (2021d). Emotions and entrepreneurial finance: The valuation effects of new venture teams' affects in initial coin offerings. UCLA Working Paper.

Park, K., Kim, K., \& Hong, Y. (2019). Beauty, gender, and online charitable giving. SSRN Working Paper.

Patel, C. P., \& Wolfe, M. T. (2019). In the eye of the beholder? The returns to beauty and IQ for the self-employed. Strategic Entrepreneurship Journal, 15, 487-525. https://doi.org/10.1002/sej.1323

Phelps, E. S. (1972). The statistical theory of racism and sexism. American Economic Review, 62(4), 659-661.

Philippi, S., Schuhmacher, M., \& Bastian, N. (2021). Attracting investors in initial coin offerings: The relationship between signals and fundraising success. Review of Corporate Finance, 1, 455-485.

Preacher, K. J., \& Hayes, A. F. (2004). SPSS and SAS procedures for estimating indirect effects in simple mediation models. Behavior Research Methods, Instruments, \& Computers, 36(4), 717-731.

Price, M. K. (2008). Fund-raising success and a solicitor's beauty capital: Do blondes raise more funds? Economics Letters, 100(3), 351-354.

Ravina, E. (2019). Love \& loans: The effect of beauty and personal characteristics in credit markets. Working Paper.

Rhodes, G. (2006). The evolutionary psychology of facial beauty. Annual Review of Psychology, 57(1), 199-226.

Ritter, J. R. (1991). The long-run performance of initial public offerings. The Journal of Finance, 46(1), 3-27.

Ruffle, B. J., \& Shtudiner, Z. (2015). Are good-looking people more employable? Management Science, 61(8), $1760-1776$.

Schultz, P. (2003). Pseudo market timing and the long-run underperformance of IPOs. The Journal of Finance, 58(2), 483-517.

Stoker, J. I., Garretsen, H., \& Spreeuwers, L. J. (2016). The facial appearance of CEOs: Faces signal selection but not performance. PLoS One, 11(7), 1-11.

Stroe, S., Sirén, C., Shepherd, D., \& Wincent, J. (2020). The dualistic regulatory effect of passion on the relationship between fear of failure and negative affect: Insights from facial expression analysis. Journal of Business Venturing, 35(4), 105948.

Tsay, C.-J. (2020). Visuals dominate investor decisions about entrepreneurial pitches. Academy of Management Discoveries, 7 , 343-366. https://doi.org/10.5465/amd.2019.0234

Warnick, B. J., Davis, B. C., Thomas, H., Allison, T. H., \& Anglin, A. H. (2021). Express yourself: Facial expression of happiness, anger, fear, and sadness in funding pitches. Journal of Business Venturing, 36(4), 106109.

Yermack, D. (2017). Corporate governance and blockchains. Review of Finance, 21(1), 7-31.

How to cite this article: Colombo, M. G., Fisch, C., Momtaz, P. P., \& Vismara, S. (2022). The CEO beauty premium: Founder CEO attractiveness and firm valuation in initial coin offerings. Strategic Entrepreneurship Journal, 16(3), 491-521. https://doi.org/10.1002/sej.1417 


\section{APPENDIX}

TABLE A1 Variables, descriptions, and data sources

Variable Description

Data source(s)

Panel A: Dependent variables

Firm valuation (log.)

The funding amount raised in the ICO in \$m (log.).

BHAR

Buy-and-hold arithmetic return. The return of the token over a holding period of 6 months after its first trading day.

Panel B: Independent variable

CEO attractiveness

Panel C: Mediators

Trustworthiness

Competence

Likability

Intelligence

Panel D: Moderators

Firm-related sentiment

Market-related sentiment
Investors' average rating of founder CEO attractiveness on a scale of 1 (=very unattractive) to 10 (=very attractive).

Investors' average rating of CEO perceived trustworthiness on a scale of 1 (=not trustworthy at all) to 10 (=very trustworthy).

Investors' average rating of CEO perceived competence on a scale of 1 (=not competent at all) to 10 (=very competent).

Investors' average rating of CEO perceived likability on a scale of 1 (=not likable at all) to 10 (=very likable).

Investors' average rating of CEO perceived intelligence on a scale of 1 (=not intelligent at all) to 10 (=very intelligent).

The variable is computed using Natural Language Processing (NLP) and employing various common dictionaries, such as QDAP, Harvard IV, and LoughranMcDonald (with qualitatively similar results). The NLP approach extracts the polarity of expressed opinion from the firms' white paper. A higher polarity score is associated with a more positive sentiment.

Market-related sentiment is measured for the entire crypto market (i.e., ICOs and cryptocurrencies in general) and provided by Thomson Reuters
ICObench, other ICO websites $^{\text {a }}$

Coinmarketcap

Own survey

Own survey

Own survey

Own survey

Own survey

ICO firms' white papers

\section{Thomson Reuters}

MarketPsych 
TABLE A1 (Continued)

Variable

Panel E: Control variables

CEO characteristics

Young

Old

Female

Asian

Black

Team characteristics

$\mathrm{PhD}$

Master's

Business degree

Technical degree

Team size

\section{Description}

Data source(s)

MarketPsych. The index is

constructed via a lexical analysis

obtained from more than 2,000

news sources included in

LexisNexis and 800 social media

platforms (Twitter, Reddit, etc.),

on a daily basis. Specifically, we

use the "buzz index," which

measures the expression intensity

and is, therefore, a good proxy for

the overall crypto sentiment. For

details, see Drobetz et al. (2019).

A dummy variable that equals one if

Linkedln

the CEO is less than 30 years old, and zero otherwise.

A dummy variable that equals one if the CEO is more than 40 years old, and zero otherwise.

A dummy variable that equals one if the CEO is female, and zero otherwise.

A dummy variable that equals one if the CEO is Asian, and zero otherwise.

A dummy variable that equals one if the CEO is black, and zero otherwise.

The fraction of team members with a $\mathrm{PhD}$ degree.

The fraction of team members with a Master's degree, but without a PhD degree.

The fraction of team members with an undergraduate or graduate degree in a business or businessrelated field (e.g., management, economics, and finance).

The fraction of team members with an undergraduate or graduate degree in a technical field (e.g., engineering and computer science).

The number of team members in the ICO firm (log.) Linkedln

Linkedln

Linkedln

CEO picture

CEO picture

Linkedln

LinkedIn

LinkedIn

ICObench 
TABLE A1 (Continued)

\begin{tabular}{|c|c|c|}
\hline Variable & Description & Data source(s) \\
\hline $\begin{array}{l}\text { Team's general professional } \\
\text { experience }\end{array}$ & $\begin{array}{l}\text { Team's general professional } \\
\text { experience in years, summarized } \\
\text { across all team members and } \\
\text { normalized by team size. }\end{array}$ & Linkedln \\
\hline Team's crypto experience & $\begin{array}{l}\text { Experience in the crypto-industry in } \\
\text { years, summarized across all team } \\
\text { members and normalized by team } \\
\text { size. }\end{array}$ & Linkedln \\
\hline \# Advisors & $\begin{array}{l}\text { The number of advisors associated } \\
\text { with the ICO firm. }\end{array}$ & ICObench \\
\hline \# Linkedln contacts & $\begin{array}{l}\text { The number of social network } \\
\text { contacts on Linkedln. }\end{array}$ & Linkedln \\
\hline \multicolumn{3}{|l|}{ ICO characteristics } \\
\hline Firm age & $\begin{array}{l}\text { The time elapsed between founding } \\
\text { the firm and the ICO start in } \\
\text { months. }\end{array}$ & Linkedln \\
\hline Pre-ICO & $\begin{array}{l}\text { A dummy variable that equals one if } \\
\text { the firm conducted a pre-ICO, and } \\
\text { zero otherwise. }\end{array}$ & ICObench \\
\hline ICO duration & $\begin{array}{l}\text { The difference in months between } \\
\text { the ICO end and the ICO start. }\end{array}$ & ICObench \\
\hline \# competing ICOs & $\begin{array}{l}\text { The number of ICOs whose time } \\
\text { period between their specific ICO } \\
\text { start and end dates overlaps with } \\
\text { the time period of the focal ICO. }\end{array}$ & ICObench \\
\hline ICO rating & $\begin{array}{l}\text { The average overall rating for an } \\
\text { ICO. }\end{array}$ & ICObench \\
\hline Bounty & $\begin{array}{l}\text { A dummy variable that equals one if } \\
\text { the firm has a bounty program in } \\
\text { place, and zero otherwise. }\end{array}$ & Firm websites \\
\hline KYC & $\begin{array}{l}\text { A dummy variable that equals one if } \\
\text { the firm has a know-your- } \\
\text { customer (KYC) procedure, and } \\
\text { zero otherwise. }\end{array}$ & ICObench \\
\hline Open source & $\begin{array}{l}\text { A dummy variable that equals one if } \\
\text { the firm publishes open-source } \\
\text { code on GitHub, and zero } \\
\text { otherwise. }\end{array}$ & GitHub \\
\hline Existing blockchain & $\begin{array}{l}\text { A dummy variable that equals one if } \\
\text { the firm uses a pre-existing } \\
\text { blockchain, such as Ethereum, and } \\
\text { zero otherwise. }\end{array}$ & ICObench \\
\hline Token supply & The number of issued tokens (log.). & Coinmarketcap \\
\hline Lock-up & $\begin{array}{l}\text { A dummy variable that equals one if } \\
\text { the firm has a lock-up program for } \\
\text { their team members in place, and } \\
\text { zero otherwise. }\end{array}$ & Firm websites \\
\hline
\end{tabular}

${ }^{\mathrm{a}}$ The valuation data were mainly obtained from ICObench. We cross-validated the data using information from other ICOcompiling sites, such as ICOdrops, CoinSchedule, and ICO firms' websites. 